\title{
Assessing Fiscal Space: An Update and Stocktaking
}




\section{INTERNATIONAL MONETARY FUND}

\section{IMF POLICY PAPER}

\section{ASSESSING FISCAL SPACE: AN UPDATE AND STOCKTAKING}

IMF staff regularly produces papers proposing new IMF policies, exploring options for reform, or reviewing existing IMF policies and operations. The following documents have been released and are included in this package:

- A Press Release summarizing the views of the Executive Board as expressed during its May 11, 2018 consideration of the staff report.

- The Staff Report, prepared by IMF staff and completed on April 11, 2018 for the Executive Board's consideration on May 11, 2018.

The IMF's transparency policy allows for the deletion of market-sensitive information and premature disclosure of the authorities' policy intentions in published staff reports and other documents.

Electronic copies of IMF Policy Papers

are available to the public from

http://www.imf.org/external/pp/ppindex.aspx

\section{International Monetary Fund Washington, D.C.}


June 27, 2018

\section{IMF Board Takes Stock of Work on Fiscal Space}

On May 11, 2018, the Executive Board of the International Monetary Fund (IMF) discussed a paper entitled Assessing Fiscal Space: An Update and Stocktaking. It reviews the implementation of the fiscal space framework developed in the paper Assessing Fiscal Space: An Initial Consistent Set of Considerations, which was published on December 15, 2016.

The framework outlined in the paper focuses on assessing the availability of space, but not its use. The paper stresses that the use of fiscal space is informed by many other considerations to be discussed during Article IV consultations. For instance, it is entirely consistent for a country with fiscal space to not use it or indeed to actually need to bolster it further, especially in the current cyclical upswing.

During 2017-2018, the framework was piloted in the Article IV consultations of 34 advanced economies and emerging markets, comprising almost 80 percent of global GDP in PPP terms. Fiscal space is defined as the room for undertaking discretionary fiscal policy relative to existing plans without endangering market access and debt sustainability. The framework is multi-dimensional, with IMF staff judgment and country-specific factors playing a significant role in the final judgment. It was developed in response to the need to provide a more systematic approach to assessing fiscal space in the context of Fund surveillance. It serves as a tool to inform assessments of the availability of fiscal space over a three to four year horizon.

The paper finds that the pilot met its key objectives. The framework generally worked well across the various pilot countries, generating assessments that were broadly in line with its underlying logic and indicators. The implementation of the framework also revealed a few potential areas for modification to further support fiscal space assessments in countryspecific contexts, such as exposure to shocks, economic structure and level of development. Such extensions include a more formal integration of contingent liabilities, as well as adjustments to capture the specificities of commodity producers and low-income countries who obtain a significant amount of external market or other non-concessional financing.

\section{Executive Board Assessment ${ }^{1}$}

\footnotetext{
${ }^{1}$ An explanation of any qualifiers used in the summing up can be found here:

http://www.imf.org/external/np/sec/misc/qualifiers.htm.

Washington, D.C. 20431 • Telephone 202-623-7100 • Fax 202-623-6772 • www.imf.org
} 
Executive Directors welcomed the opportunity to discuss the update of the framework for the assessment of fiscal space and the experience with the pilot application of the framework. Most Directors agreed that this experience indicated that the framework had provided a useful approach for assessing fiscal space in a consistent manner across countries, supported engagement with the authorities, and had been appropriately applied.

Going forward, Directors noted that the framework was a work in progress and needs to be strengthened further in several respects including the ability to incorporate country-specific circumstances, evaluation of funding conditions, contingent liabilities, and intergenerational considerations. Most Directors supported an extension of the framework to commodity producers and low-income countries which obtain a significant amount of external or other non-concessional financing, with appropriate modifications, while ensuring consistency with the debt sustainability and external sector assessment frameworks. Many Directors noted that additional refinements and extensions are necessary before the framework is integrated systematically into Fund surveillance, and looked forward to further discussions with the Board. Many others, while recognizing the scope for further refinements, supported moving forward in using the framework more systematically as a tool for Fund surveillance.

Directors stressed the importance of clearly communicating the factors underlying staff's assessment of fiscal space to the authorities and markets, particularly with respect to the distinction between the availability of fiscal space and its use. While the assessment of available space is an important input for analyzing fiscal policy, a view on the use of fiscal space needs to be based on additional criteria, requiring a broader analysis of factors and country-specific circumstances. In the current cyclical upswing, many Directors underlined the need to ensure that the application of the framework is symmetric. In particular, policy advice should remain mindful of the ongoing broader multilateral surveillance messages, among others, on the need to rebuild fiscal buffers where needed and to maintain adequate cushions to enhance resilience to shocks.

Directors underscored that an assessment of fiscal space is sensitive to the initial state of the economy and that it is a forward-looking, conjunctural, and dynamic concept. This requires the assessments to consider the consequence of alternative paths for fiscal policy and likely market reaction, while adequately accounting for uncertainty.

Directors underscored that well-designed fiscal rules play an important role in safeguarding policy credibility, maintaining market access and contributing to building fiscal space. With this, most Directors considered it appropriate that the fiscal space assessment is made with and without the existing fiscal rules. Directors also stressed that the fiscal space assessment is not an assessment of the rules themselves, although some noted that wide and persistent gaps between assessments with and without rules could justify a reevaluation of the rules with careful consideration of credibility risks. A few Directors emphasized the need for the framework to incorporate union-wide considerations in the assessment of space for members of currency unions where fiscal rules play an important role in macroeconomic stability, together with effective monetary policy. 
Directors underscored that the assessment of fiscal space should not be a mechanical exercise in bilateral surveillance but should inform the wider fiscal policy discussion with authorities. Directors broadly concurred that a framework-based assessment of fiscal space every three years should suffice, with more frequent assessments in the case of large macroeconomic shocks, substantive shifts in funding availability or market sentiment, or significant changes to fiscal policy and rules. 


\section{INTERNATIONAL MONETARY FUND}

April 11, 2018

\section{ASSESSING FISCAL SPACE: AN UPDATE AND STOCKTAKING}

\section{EXECUTIVE SUMMARY}

This paper reviews the experience with the fiscal space assessment framework that was piloted during 2017-18. In 2016, staff proposed an operational definition of fiscal space and a new four-stage framework for its assessment. These were discussed informally by the Board in June, and a Board paper "Assessing Fiscal Space: An Initial Consistent Set of Considerations" incorporating Directors' views was published in December. Fiscal space was narrowly defined as the room for undertaking discretionary fiscal policy relative to existing plans without endangering market access and debt sustainability. The framework was developed in response to the need to provide a more systematic approach to assessing fiscal space in the Fund's surveillance. It was designed as a tool to inform the availability of fiscal space over a 3 to 4 year horizon for discretionary action, as opposed to the optimality of its use. Indeed, it was stressed that the availability of space does not necessarily mean that it should be used or should not be further expanded. The framework was piloted in the Article IV consultations of 34 advanced economies and emerging markets, comprising almost 80 percent of global GDP in PPP terms.

The pilot met its key objectives. The framework generally worked well across the various pilot countries, generating fiscal space assessments that were broadly in line with its underlying logic and indicators. Article IV staff reports were strengthened through more pointed, clear, and consistent discussions of fiscal space. The assessments helped inform the fiscal policy advice and, in several instances, supported the dialogue with authorities. Overall, while the assessments did diverge in a few cases, there was little tension created by assessing space with and without fiscal rules. The framework also supported evidence-based and even-handed internal review of country documents, and was implemented in a relatively cost-effective way.

Despite elevated levels of public debt, most countries had at least some space. This reflected generally low financing needs, extended debt maturities, a greater share of local currency borrowing, and favorable interest rate-growth differentials. As a result, there could, in principle, be scope for near-term discretionary fiscal policy in some countries, if justified. Such discretionary action could take the shape of either an outright fiscal stimulus or a more gradual pace of fiscal consolidation. In the current conjuncture, however, strong and broad-based growth provides many countries an opportunity to begin rebuilding buffers, improve government balances, and reduce public debt, notwithstanding the existence of some fiscal space. As 
growth returns to potential, fiscal stimulus loses its effectiveness while the cost of fiscal consolidation diminishes.

In general, advanced economies were found to have more space than emerging markets mainly because their financing is more secure, largely reflecting greater credibility and institutional strength. Of the pilots, 6 countries had substantial, 17 some, and 11 limited fiscal space. All of the countries with substantial space, bar one, were advanced economies, and only three (European economies) were found to have limited space among advanced economies.

Fiscal space assessments can be sensitive to the prevailing state of the economy. Fiscal space is a forward-looking and dynamic concept such that today's fiscal space depends on the future effect of policies given the particular conjuncture the economy faces. For instance, in the face of a severe negative shock, a large fiscal consolidation could actually reduce fiscal space by dampening growth. Alternatively, a temporary stimulus could create fiscal space and improve medium-term debt prospects, if it is used wisely, e.g. to fund investment in productive infrastructure, support structural reforms, or help repair private balance sheets. Conversely, a poorly executed stimulus could deplete fiscal space and put upward pressure on financing costs. Therefore, fiscal space assessments need to consider the consequence of alternative paths for fiscal policy and their likely market reaction, while adequately accounting for uncertainty.

Fund advice on the use of fiscal space varied across the pilots, reflecting the distinction between the existence of space and its optimal use. At the current conjuncture, with narrowing or positive output gaps and an uncertain near-term outlook for financing conditions, staff's advice typically focused on building buffers in countries with relatively less fiscal space, with any available space deployed to moderate the pace of consolidation if warranted. Where space was more abundant, the recommendation was for fiscal policy to support structural reforms or to undertake discretionary measures to boost long-term growth potential, such as through infrastructure spending.

The implementation of the framework revealed a few potential areas for modification. Overall, the pilots confirmed that it is crucial to assess fiscal space in a country-specific context that accounts for the country's exposure to shocks, economic structure and level of development. Accordingly, the paper proposes some adjustments that could be made to further strengthen the framework as it is integrated as a tool for Fund surveillance:

Refinements. Where data allows, the framework could include indicators to better capture fiscal risks from contingent liabilities. Indicators associated with the potential behavior of risk premia could be added when setting the context in the first stage. In the second stage, rather than uniform thresholds for indicators based on the level of 
development, there may be a case for tailoring these for different types of economies (e.g., reserve currency issuers). For some countries, a somewhat longer horizon for assessing the sustainability of debt and financing may also be appropriate. In the third stage, when warranted, customized scenarios featuring a different scale and composition of discretionary fiscal actions could be added to the standardized simulations, in order to better reflect country specificities and inform the policy dialogue.

Extensions. While the broad logic of the framework still applies, the pilot experience pointed to areas where it needs to be adjusted to capture the specificities of commodity producers. In particular, the availability of public assets, exposure to volatility, and alternative metrics of the fiscal position need to be taken into account. The framework could also be modified to apply to low-income countries that have access to a significant amount of external market or other non-concessional financing. 


\section{Approved By}

Sanjaya Panth and

Abdelhak Senhadji
This paper was prepared by an interdepartmental team led by M. Syed (SPR) and M. Moreno Badia (FAD). Mr. Syed coordinated the project and the team comprised E. Lundback (SPR, principal author), C. Lundgren, B. Sbrancia (both SPR) and J. Reynaud (FAD). The work was supervised by M. Flanagan and V. Haksar (both SPR) and C. Pattillo (FAD).

\section{CONTENTS}

Acronyms and Abbreviations

ASSESSING THE PILOT EXPERIENCE

A. How Did the Fiscal Space Framework Work in Practice?

B. What Did We Learn About Fiscal Space in the Global Conjuncture?

C. Were the Objectives of the Pilot Met?

EXTENDING THE FRAMEWORK TO STRENGTHEN FISCAL SPACE ANALYSIS

$\begin{array}{lr}\text { A. Low-income Countries } & \frac{33}{33} \\ \text { B. Commodity Producers } & \frac{36}{38} \\ \text { C. Contingent Liabilities } & -\frac{38}{}\end{array}$

FISCAL SPACE IN SURVEILLANCE: CONCLUSIONS AND A WAY FORWARD

\section{BOXES}

1. Fiscal Space Assessment: Summary of the Framework

2. Fiscal Rules, Fiscal Space and Revisions of Rules

3. Fiscal Space and Long-Term Demographic Pressures ________

4. What Can Be Learnt from the Simulations? __________

5. Assessing Space for LICs with Market Access: Potential Additional Indicators ___ _ _ _

6. Assessing Space for Commodity Producers: Potential Additional Indicators______

7. Incorporating Contingent Liabilities: Potential Additional Indicators ____

\section{FIGURES}

1. Fiscal Space Assessment: A Stylized Illustration of the Sifter Approach_________

2. The Global State of Fiscal Space________

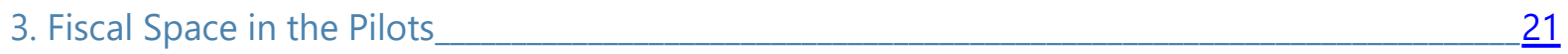

4. Fiscal Space Pilots: Evolution of Selected Indicators ____ $\underline{21}$

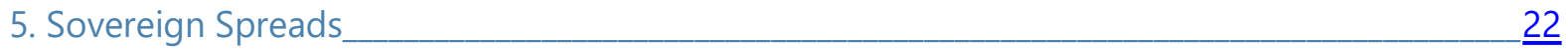


6. Debt Profile Indicators_______

7. Public Debt Level____

8. Gross Financing Needs ______ 2

9. Assumed Medium-Term Adjustment____________ $\underline{25}$

10. Old Age Dependency and Long-Term Adjustment Needs_____ $\underline{25}$

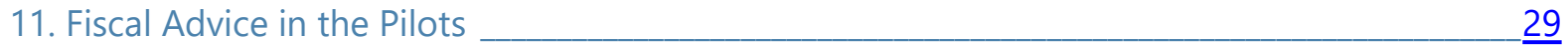

12. Contingent Liability Realizations _______ $\underline{39}$

13. Costs and Frequency of Fiscal Risk Realizations ________ $\underline{40}$

\section{TABLES}

1. Fiscal Space Pilots: Country List_________ $\underline{8}$

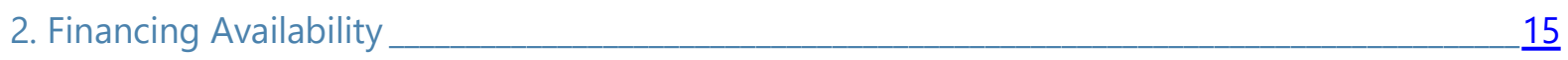

3. Debt Burden Indicators Under Baseline and Stress Tests _____

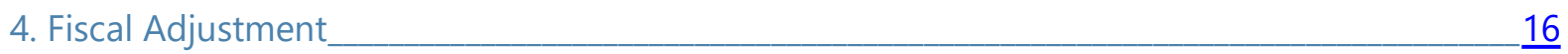

5. Fiscal Space Assessments: Pilot Results_______

\section{ANNEXES}

I. Fiscal Space Framework: Simulations

II. Fiscal Space Assessments in the Pilots $\underline{46}$

III. Indicators of Contingent Liabilities 


\section{Acronyms and Abbreviations}

$\begin{array}{ll}\text { CAPB } & \text { Cyclically Adjusted Primary Balance } \\ \text { DIGNAR } & \text { Debt, Investment, Growth, and Natural Resources } \\ \text { DSA } & \text { Debt Sustainability Analysis } \\ \text { ESR } & \text { External Sector Report } \\ \text { FAD } & \text { Fiscal Affairs Department } \\ \text { GDP } & \text { Gross Domestic Product } \\ \text { GFN } & \text { Gross Financing Needs } \\ \text { GFSM } & \text { Government Finance Statistics Model } \\ \text { IMF } & \text { International Monetary Fund } \\ \text { LIC } & \text { Low income countries } \\ \text { LIC DSF } & \text { Debt Sustainability Framework for Low-Income Countries } \\ \text { MAC DSA } & \text { Debt Sustainability Analysis for Market-Access Countries } \\ \text { OECD } & \text { Organization for Economic Co-operation and Development } \\ \text { PPP } & \text { Purchasing Power Parity } \\ \text { RES } & \text { Research Department } \\ \text { SFA } & \text { Stock-flow Adjustment } \\ \text { SGP } & \text { Stability and Growth Pact } \\ \text { SOE } & \text { State Owned Enterprise } \\ \text { WEO } & \text { World Economic Outlook }\end{array}$




\section{INTRODUCTION}

1. In 2016, staff proposed a new framework for assessing fiscal space. The framework was discussed informally by the Board in June, and a Board paper "Assessing Fiscal Space: An Initial Consistent Set of Considerations" incorporating Directors' views was published in December.

2. It was developed in response to the need to provide a more systematic approach to assessing fiscal space in the Fund's surveillance. This was an element that was lacking in the Fund's toolkit, which, if available, would help in informing policy advice at both the bilateral and multilateral levels. During the mediocre recovery from the global crisis, a central part of the Fund's global messaging for many years was that those countries with fiscal space should use it as part of a more forceful, three-pronged approach to combating the downturn. More recently, as a global recovery has taken hold, the focus has pivoted toward countries needing to take advantage of the cyclical upturn to rebuild buffers, with its pace calibrated based on the extent of fiscal space and any remaining economic slack. However, the Fund had not been explicit about what fiscal space meant or how much it considered its member countries to have.

3. The framework acknowledged the complexity of analyzing fiscal space. Fiscal space was recognized as being a multi-dimensional concept that is challenging to operationalize, with various empirical strategies found in the literature. Practically speaking, fiscal space was therefore difficult to pin down purely through a mechanical rule or threshold. The paper proposed a definition of fiscal space and a four-stage approach for its qualitative assessment, based on considerations drawn mainly from previous work by Fund staff on fiscal risks related to liquidity and sustainability. It suggested indicators that could guide each stage of the analysis and noted that the framework would be refined over time, with experience and in response to new methods developed by staff. The paper clarified that while the resulting fiscal space assessments would be an input into country teams' fiscal policy advice, the apparatus itself did not aim to answer the question of when or how fiscal space should be used.

\section{The framework was implemented in the Article IV consultations of $\mathbf{3 4}$ advanced} economies and emerging markets, comprising almost 80 percent of global GDP in PPP terms (Table 1). ${ }^{1}$ The pilots were selected based on the WEO classification of Group A countries as of October 2015, representing a diverse set of macroeconomic characteristics and geographic coverage. The aim was to provide a tool to support surveillance, by allowing fiscal space assessments to be based on a consistent definition and set of considerations. The Staff Reports of the pilot economies featured a clear assessment of the degree of fiscal space available, justified using key considerations from the framework. In turn, these assessments formed one of the key

\footnotetext{
${ }^{1}$ All of these countries employ the Debt Sustainability Analysis for Market-Access Countries (MAC DSA). While part of the pilot, Angola, Chile, India and Switzerland have not yet completed their Article IV cycles and have therefore been excluded from this paper.
} 
inputs informing fiscal policy advice. In cases where fiscal rules existed, staff also discussed the extent to which they were a constraint on the assessment and advice.

Table 1. Fiscal Space Pilots: Country List

\section{African Department}

1. Nigeria

2. South Africa

Asia Pacific Department

3. Australia

4. China

5. Indonesia

6. Japan

$7 . \quad$ Korea

8. Malaysia

9. Philippines

$10 . \quad$ Thailand

European Department

11. France

$12 . \quad$ Germany

13. Israel

$14 . \quad$ Italy

15. Netherlands

16. Poland

$17 . \quad$ Russia

18. Spain

19. Sweden

20. Turkey

21. United Kingdom

\section{Middle East and Central Asia Department}

22. Algeria

23. Egypt

24. Iran

25. Kazakhstan

26. Morocco

27. Pakistan

28. Saudi Arabia

Western Hemisphere Department

29. Argentina

30. Brazil

31. Canada

32. Colombia

33. Mexico

34. United States

Note: Angola, Chile, India, and Switzerland are also part of the pilot but have not completed their Article IV cycles at the time of this paper. For the Euro Area, the framework was applied to its member countries indicated above, and a discussion of fiscal space on this basis was included in its Staff Report. 
5. Based on experience with the pilots, this paper takes stock of the fiscal space framework and proposes a strategy for using it as a tool of Fund surveillance. The paper describes how the framework was implemented, identifies key insights and challenges, discusses possible refinements and extensions, and proposes next steps in terms of its application in surveillance.

6. The rest of the paper is organized as follows. The first section briefly reviews the concept of fiscal space used by staff, including clarifying the distinction between its availability and use and its relationship with fiscal rules and societal objectives such as inter-generational equity. The second section reports on the pilot experience, beginning with a discussion of how the framework was applied in practice, including the specific indicators used to inform each of its stages. It then reviews the fiscal space assessment results, drawing some key insights and stylized facts regarding fiscal space in the current global conjuncture. Finally, it evaluates the extent to which the pilot met its key objectives and introduces some technical refinements. Based on the findings, the third section discusses potential options for more extensive augmentation, including with regard to low-income countries, commodity producers, and risks from contingent liabilities. The penultimate section presents a proposal for integrating the framework as a tool for Fund surveillance going forward, together with suggestions for a supporting analytical agenda. The paper concludes with issues for discussion.

\section{FISCAL SPACE: CONCEPTUAL AND ANALYTICAL ISSUES}

7. The 2016 Board paper proposed a narrow and intuitive definition of fiscal space that would be amenable to operationalization. Fiscal space is defined as the room to raise spending or lower taxes relative to a pre-existing baseline, without endangering market access and debt sustainability. Such discretionary fiscal policy could take the form of either an outright fiscal stimulus or a slower pace of fiscal consolidation. When a government considers a looser fiscal stance, it needs to gauge whether it can implement it without undermining the sustainability of the country's public finances and risking an unfavorable reaction from financial markets. The more confident it can feel about this, the more fiscal space it is deemed to have, and the larger the increase in spending or reduction in taxes can be relative to the baseline. Conversely, the riskier the market and fiscal outlook, the more limited is the government's scope for a looser fiscal stance, with a premium instead on building buffers.

\section{By abstracting from any considerations other than financing availability and fiscal} sustainability, this definition can be seen as a relatively pure concept of fiscal space.

Countries may sometimes choose to adopt fiscal rules or embed societal preferences (such as those associated with managing resources from the point of view of inter-generational equity) in their conduct of fiscal policy. Under staff's definition, these would act, in the first instance, as constraints on the use of fiscal policy rather than determinants of its availability per se. 


\section{Even within this circumscribed definition, a comprehensive analytical approach is} necessary. The extent to which a country has room to raise spending or lower taxes depends on multiple factors, including the availability of financing on favorable terms and the risk of market perceptions sharply increasing funding costs, the sustainability of the level and trajectory of public debt and financing needs, and the realism of the medium and long-term fiscal adjustment needed to achieve prudent debt ratios. At the core of the approach is identifying fiscal risks from different angles, notably by considering indicators of market access and debt dynamics that have historically been associated with fiscal stress episodes, as well as by allowing for country-specific shock scenarios.

10. Crucially, the framework emphasized that the dynamic impact that discretionary fiscal policy could have on financing availability and debt sustainability also needs to be taken into account, and that this impact is sensitive to prevailing economic conditions such as the output gap, relative spending needs, institutional capacity, and monetary policy settings. This captures the notion that fiscal space is a forward-looking and dynamic concept such that today's fiscal space depends on the future effect of policies given the particular conjuncture that the economy faces. For instance, in the face of a large negative shock, a large fiscal consolidation could actually reduce fiscal space by dampening GDP growth. Alternatively, a temporary stimulus could create fiscal space and improve medium-term debt prospects, especially if it is used to fund investment in productive infrastructure, support structural reforms, or help repair balance sheets of the private sector. Therefore, fiscal space needs to be assessed keeping in mind the current state of the economy, and under alternative assumptions regarding the composition of fiscal policy and the likely market reaction, while adequately accounting for uncertainty.

\section{Accordingly, a single metric is eschewed in favor of a multi-faceted approach that} leverages indicators and tools developed by staff over many years. This approach enables a qualitative assessment of the degree of fiscal space in a country, built around four stages (summarized in Box 1; for details, see IMF, 2016a). Broadly speaking, the framework rests on two main considerations, which are evaluated under different plausible states of the world:

- financing - the extent to which the government can expect to have access to market funding at reasonable rates.

- sustainability - the extent to which public debt and annual financing needs (composed of the budget deficit and repayment of debt coming due) of the government remain sustainable.

\section{Applying this holistic approach, country teams form a bottom-line assessment:}

- Fiscal space is limited when no (or at most only marginal) fiscal loosening compared to the baseline can be contemplated.

- There is some fiscal space when there are some concerns about financing, fiscal sustainability, or credibility, but meaningful temporary fiscal measures are possible within certain limits, if there is an economic case for such measures. 
- Fiscal space is substantial when financing, fiscal sustainability and credibility considerations suggest no significant constraint to undertaking temporary fiscal measures, if there is an economic case for them. While the extent of relaxation and type of measures still require calibration, fiscal policy can generally be looser for longer when space is substantial.

The final assessment of the degree of fiscal space ultimately relies on staff judgement based on the signals provided by the different stages of the framework, as well as any additional countryspecific factors, indicators, and analyses.

13. The framework is applicable at all stages of the economic cycle. It can inform both the scope for stimulus and how fast to consolidate. Where the economy is in a cyclical downturn or needs infrastructure investment or structural reforms to boost potential growth, the relative degree of fiscal space can inform how much scope exists for fiscal support. Alternatively, where the economy is enjoying a cyclical upturn or otherwise needs consolidation, it can help inform the desirable pace of fiscal withdrawal or building of buffers. That said, as discussed below, the existence of space does not imply that it should necessarily be used. For example, in the current conjuncture, decisive action is needed in many countries to strengthen fiscal buffers taking full advantage of the cyclical upswing, notwithstanding the existence of fiscal space.

\section{Box 1. Fiscal Space Assessment: Summary of the Framework}

The four stages of the fiscal assessment framework reflect inter-related aspects that need to be considered when assessing fiscal sustainability: (i) the cyclical and structural state of the economy; (ii) the availability of financing on favorable terms and the risk of market perceptions sharply increasing funding costs; (iii) the sustainability of the level and trajectory of public debt and deficits over the medium and long term; and (iv) the sensitivity of fiscal sustainability in terms of debt and financing needs under reasonable stress events and expansionary fiscal scenarios.

Macroeconomic context. Making an initial assessment of context-including domestic and external conditions, and structural gaps - which has a bearing on the likely economic and risk premium impact of any fiscal policy action (which is explicitly modeled in the third stage).

Market access and debt sustainability. Considering measures of fiscal sustainability under baseline policies and standardized stress scenarios. These relate to the availability of financing, the debt burden, and the fiscal adjustment needs over the medium and long-term.

Dynamic analysis of expansionary fiscal policy. Simulating discretionary fiscal policy experiments relative to the baseline, and mapping out their implications for macroeconomic outcomes (e.g., GDP and inflation), and the level and trajectory of fiscal variables, including both stocks and flows (debt and gross financing needs). These simulations rest on standardized assumptions and aim to shed light on the debt-growth tradeoff of discretionary fiscal policy, under upside and downside scenarios. Country teams exercise judgment about which scenario more likely applies in their specific conjunctural context.

Final judgment. Applying staff judgment to arrive at the final assessment of the degree of fiscal space based on the signals provided by the three stages, as well as any additional country-specific factors, indicators, and analyses. 
14. When market access or the trajectory of the debt burden is uncertain, the degree of fiscal space available can be influenced by the timing and nature of its use. If fiscal space is used wisely, underlying economic fundamentals should be strengthened, thereby supporting the fiscal position and favorable market financing. Prudent use of space can also help preserve it, for instance by dealing with certain contingent liabilities before they mushroom, e.g., by cleaning up balance sheets at an early stage (IMF, 2016b). On the other hand, unproductive use may soon eliminate fiscal space and put upward pressure on the cost of market financing.

\section{Notwithstanding this possible feedback, the framework is explicitly designed to} assess the existence of fiscal space and not its use. While the framework can help teams think through issues of use in a generic way-for instance through the simulations considered as part of the third stage-it is only geared to assessing the availability of space. The assessment of the extent of available fiscal space should certainly be an important input for the fiscal policy stance, but the final view will be based on a broader analysis of factors and country-specific circumstances - such as the cyclical state of the economy, the balance of risks, the setting of other policies, structural reform needs, distributional goals, and consistency with any existing rules or societal preferences. These broader considerations are outside the framework. Indeed, it is entirely consistent for a country to have fiscal space but to choose, or be advised, not to use it or to bolster it further. For instance, using fiscal space would generally be inadvisable when the economy is in a cyclical upswing. When the economic outlook or financing prospects are volatile, there is typically a premium on building additional buffers. More generally, the use of fiscal space is a separate matter from its existence.

\section{Under the framework, the fiscal space assessment is made both with and without considering fiscal rules, in part to examine how rules may constrain the use of available} space. This is an important feature, since it is highly relevant to understand to what extent fiscal rules are binding for the assessment of fiscal space. It is not enough to only note that there is a certain degree of fiscal space under existing rules, since the design and calibration of the rules themselves can lead to an overly generous or conservative assessment. Since fiscal rules constrain the use of fiscal space under certain situations, a "pure" measure of space abstracting from them is a useful concept. That said, well-designed fiscal rules play an important role as a policy anchor in safeguarding fiscal credibility and market access, and therefore fiscal space. Many fiscal rules have legal standing, for example those enshrined in fiscal responsibility laws. The assessment must therefore also be made taking fiscal rules into account. In this connection, it should be stressed that the fiscal space assessment is not an assessment of the rules themselves, which would require deeper analysis. While a large and persistent divergence between the fiscal space assessment with and without rules could serve as an indicator that may prompt a consideration of the appropriateness of a fiscal rule, this is a separate and broader issue as discussed in Box 2 . 


\section{Box 2. Fiscal Rules, Fiscal Space and Revisions of Rules}

Well-designed fiscal rules can play an important role in safeguarding policy credibility and market access, thereby contributing to building fiscal space. As part of the institutional setting and policy framework to soundly manage public finances, fiscal rules are used to constrain fiscal policy discretion and promote fiscal discipline. They impose long-lasting constraints on fiscal policy by setting numerical limits on key fiscal indicators. As such, well-designed fiscal rules support explicit medium-term objectives and encourage building buffers in good times, while leaving flexibility in the face of shocks or exceptional circumstances. In so doing, they promote fiscal sustainability and the appropriate use of public resources.

To meet their objectives, fiscal rules need to be re-evaluated from time to time and refined or revised if warranted. In some cases, the design of fiscal rules may be flawed from inception, as revealed during the global crisis when several countries faced too stringent constraints because the existing rules-based fiscal framework lacked escape clauses (Celasun and others, 2015). But even if appropriately designed at the time of introduction, changes to the economic environment can render them less suitable to achieve fiscal policy objectives. This is not to suggest that existing rules should be breached (i.e. deviated from or suspended in a manner inconsistent with the existing legal framework), as such breaches could have significant financial, legal, reputational, and political costs (see, for example, Diaz-Kalan, Popescu and Reynaud (2018), for a discussion on the costs of breaching EU fiscal rules). Rather the question is to determine to what extent they should be adapted to enable sound fiscal policy, considering the costs and challenges of changing the rule. This requires having a view on what is the appropriate fiscal policy.

In deciding whether revisions to the fiscal rules are warranted, the leeway for using existing fiscal space is one of many considerations. Well-designed rules should support good fiscal policy. From that perspective, there is a broad consensus, laid out in several IMF publications (Daniel and others, 2006; Blanchard, Dell'Ariccia, and Mauro, 2010; IMF, 2013 and 2017a) that fiscal policy should be prudent (keep debt on a sustainable path and manage fiscal risks adequately); countercyclical when feasible (mostly by letting automatic stabilizers operate in a symmetric way); growth-friendly (to support potential output); and inclusive (ensuring that the poor and the middle class share in the growth dividend and can adapt to a changing economy). To the extent that an existing rule tends to persistently and by large magnitudes prevent either the desirable use of existing fiscal space or rebuilding fiscal space when required, it may lead to undesirable outcomes in some respects, including procyclicality and a greater exposure to fiscal crisis. 1/ Here, and if differences between good policies and the rule cannot be accommodated within the rule (by using all forms of flexibility, see Eyraud and others, 2018), revision of the rule should be considered. However, as costs related to rule revision can be high in several dimensions (i.e., credibility, political, fiscal, economic, and legal), any decision should be based on a thorough cost-benefit analysis and economic judgment taking into account country-specific characteristics. The joint review of fiscal policy and the rule could be done from time to time or be prompted by extraordinary economic events. Importantly, the fact that the review could be conducted from time to time does not imply that the rule would be revised at the same frequency. If the decision is made to revise the rule, there are a variety of options that range from relatively minor revisions (e.g., on the parameters) to more fundamental design changes, including the possibility of lawfully repealing or amending the rule. $2 /$

1/ For example, nominal deficit ceilings are often not binding in upswings, and therefore, do not appropriately constrain fiscal policy leading to procyclicality.

2/ For a discussion on the desirable features of second-generation fiscal rules, see Eyraud and others (2018). For more details on rule selection and calibration, see IMF (2018a and 2018b). 


\section{ASSESSING THE PILOT EXPERIENCE ${ }^{1}$}

\section{A. How Did the Fiscal Space Framework Work in Practice?}

\section{In practice, rather than being mechanically implemented, the framework's different} stages functioned like a sifter. Based on the definition of fiscal space used by staff, a few considerations - notably access to market financing and debt sustainability—if assessed negatively, already provided a strong signal that there was likely to be limited or at most some fiscal space, subject to verification under the simulations. This section describes the logic of this hierarchical approach and the indicators that were used to inform it. As will be illustrated, the different layers of the sifter were closely linked to the four stages of the framework described earlier. $^{2}$

\section{Financing Considerations}

18. The primary consideration was whether the country currently has-and is likely to retain-access to stable market financing at contained risk premia. If not, the country invariably had limited fiscal space. This condition can change over time, of course, such that a country can move from having limited to some fiscal space, and vice versa. The assessment was based on the evolution of sovereign bond spreads and debt profile indicators typically associated with the likelihood of future fiscal distress-public debt held by non-residents, public debt in foreign currency, the change in the share of short-term debt, and external financing requirements (Table 2). In this context, potential cushions provided by the availability of liquid public financial assets were also considered as a possible counterweight to an otherwise less favorable financing outlook. $^{3}$

\section{Sustainability Considerations}

19. If market financing was not expected to be a binding constraint in the near-term, the likely evolution of debt burden indicators was evaluated, including in response to plausible high-impact risks such as major fluctuations in key macroeconomic variables, or, where deemed relevant, the materialization of salient fiscal risks like contingent liabilities. In particular,

\footnotetext{
${ }^{1}$ The discussion in this paper-including the numbers in tables and figures, and policy advice-are based on analysis conducted in the lead-up to the 2016 (for Australia, Iran, and the Netherlands) or 2017 Article IV Consultation (for the other pilots), unless otherwise indicated. In a few cases there has been a subsequent Article IV consultation, but no material change in the fiscal space assessment.

${ }^{2}$ Since the first stage of the framework is primarily intended to inform the likely impact of discretionary fiscal action given the conjunctural position of the economy, which is formally modeled in the simulations run as part of the third stage, it helps for expositional clarity to discuss these together. This approach is followed in the rest of the paper.

3 The default in fiscal analysis - including in the MAC DSA-is to consider gross, not net debt, and consider net debt as a complement to gross debt, which requires a consideration of whether assets can be realistically used to repay and service debt, and whether there is reliable data on assets available. Where they are sizeable, liquid public financial assets can be a key factor in determining the amount of fiscal space a country has.
} 
the projected level and trajectory of debt and gross financing needs over the medium-term were examined under both staff's baseline and the most severe stress test considered in the MAC DSA (Table 3). If there were clear risks to debt sustainability in the baseline, the country could have at most some fiscal space, as long as it enjoyed near-term access to stable and affordable financing.

20. If debt burden indicators were deemed relatively strong, the realism of the assumed medium-term fiscal adjustment plans and the scale of longer-term pressures on the public finances were also assessed. These served as a foil against potentially over-optimistic projections that could be conveying a greater-than-warranted sense of fiscal space based on the preceding filters. For the medium term, the adjustment of the cyclically-adjusted primary balance assumed under the baseline was compared to historical cross-country experience (Table 4). For the long-term, the relative size of the adjustment of the cyclically-adjusted primary balance needed to stabilize debt ratios in the long run was assessed, taking into account demographic trends and costs associated with population aging (Box 3$)^{1}$

\begin{tabular}{|c|c|c|c|c|c|c|c|c|c|c|c|c|c|c|}
\hline \multicolumn{15}{|c|}{$\begin{array}{l}\text { Table 2. Financing Availability } \\
\text { ercent of GDP unless otherwise indicated) }\end{array}$} \\
\hline \multicolumn{7}{|c|}{ Advanced Economies } & \multicolumn{8}{|c|}{ Emerging Markets } \\
\hline \multicolumn{3}{|c|}{$\begin{array}{c}\begin{array}{c}\text { Peak sovereign bond } \\
\text { spreads } 3 /\end{array} \\
\end{array}$} & \multicolumn{3}{|c|}{ Debt profile indicators } & \multirow[b]{2}{*}{ 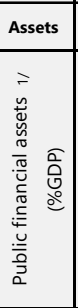 } & \multicolumn{3}{|c|}{$\begin{array}{c}\begin{array}{c}\text { Peak sovereign bond } \\
\text { spreads } 3 /\end{array} \\
\end{array}$} & \multicolumn{4}{|c|}{ Debt profile indicators } & \multirow[b]{2}{*}{ 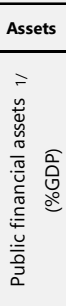 } \\
\hline 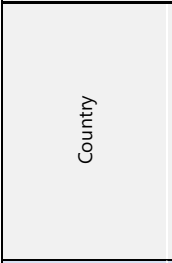 & 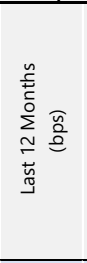 & 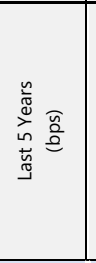 & 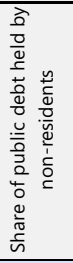 & 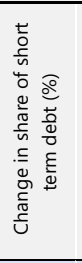 & 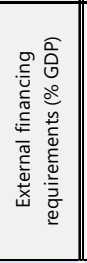 & & 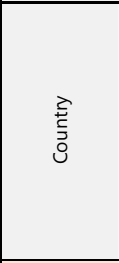 & 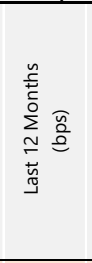 & 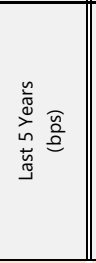 & 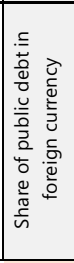 & 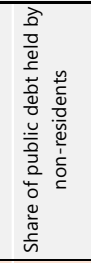 & 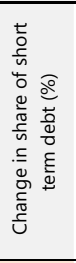 & 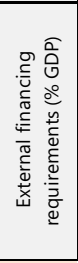 & \\
\hline Australia & 64.0 & 263.0 & 45.1 & -0.1 & $\ldots$ & 18.9 & Algeria & 435.0 & 459.0 & 9.8 & 9.8 & -7.5 & 18.3 & 4.2 \\
\hline Canada & -33.0 & 20.0 & 23.7 & -1.0 & 54.4 & 64.7 & Argentina & 479.8 & 1198.4 & 67.9 & 33.5 & 1.5 & 9.8 & $\ldots$ \\
\hline France & 66.0 & 121.9 & 58.5 & -0.2 & 0.9 & $\ldots$ & Brazil & 378.7 & 475.5 & 4.8 & 14.1 & -1.2 & 9.5 & 32.0 \\
\hline Germany & -181.2 & -42.7 & 53.7 & -0.3 & $\ldots$ & $\ldots$ & China & 154.0 & 278.0 & 0.4 & 0.8 & 0.0 & 7.4 & $32-41$ \\
\hline Israel & 171.0 & 204.7 & 13.6 & -0.2 & 8.0 & $\ldots$ & Colombia & 358.2 & 358.2 & 47.6 & 61.7 & 0.0 & 13.0 & 10.4 \\
\hline Italy & 141.5 & 205.9 & 34.1 & -0.5 & 40.2 & 20.4 & Egypt & 501.9 & 619.4 & 13.1 & 25.3 & 0.3 & 7.6 & $\ldots$ \\
\hline Japan & -204.1 & -172.3 & 9.6 & -0.8 & 7.5 & 119.0 & Indonesia & 346.0 & 346.0 & 42.6 & 65.5 & -1.0 & 7.8 & 27.4 \\
\hline Korea & 60.0 & 110.0 & 14.1 & -0.1 & 3.4 & 33.2 & Iran & $\ldots$ & $\ldots$ & $\ldots$ & 4.0 & $\ldots$ & 0.0 & 16.3 \\
\hline Netherlands & 25.0 & 51.0 & 47.0 & 0.0 & -7.8 & 35.1 & Kazakhstan & 503.0 & 556.0 & 50.8 & 1.2 & 0.0 & 81.9 & 46.0 \\
\hline Spain & 141.4 & 532.4 & 45.0 & -0.1 & 54.3 & $\ldots$ & Malaysia & 238.0 & 239.0 & 11.0 & 31.4 & -0.1 & 46.9 & $\ldots$ \\
\hline Sweden & 25.0 & 65.0 & 29.4 & -8.0 & 58.9 & $\ldots$ & Mexico & 309.0 & 348.0 & 33.7 & 50.6 & 0.3 & 13.4 & 7.9 \\
\hline United Kingdom 2/ & 117.0 & 151.1 & 23.3 & 0.4 & 205.2 & 8.7 & Morocco & 187.1 & 220.5 & 21.7 & 21.7 & -1.5 & 6.5 & 11.0 \\
\hline United States & 211.7 & 211.7 & 26.9 & 1.2 & 30.5 & 13.8 & Nigeria & 767.7 & 767.7 & 30.0 & 1.0 & -2.8 & -0.4 & 5.7 \\
\hline & & & & & & & Pakistan & 342.0 & 393.0 & 31.2 & 31.2 & 0.9 & 3.5 & $\ldots$ \\
\hline & & & & & & & Philippines & 100.0 & 130.0 & 42.5 & 42.5 & 0.4 & 6.0 & 61.0 \\
\hline & & & & & & & Poland & 134.0 & 344.0 & 34.1 & 56.0 & 0.7 & 22.1 & $\ldots$ \\
\hline & & & & & & & Russia & 175.0 & 245.0 & 22.9 & 22.9 & -4.2 & 4.7 & $\ldots$ \\
\hline & & & & & & & Saudi Arabia & 138.0 & $\ldots$ & 34.8 & 34.8 & 0.0 & 9.7 & 31.3 \\
\hline & & & & & & & South Africa & 740.0 & 746.0 & 9.9 & 36.0 & -0.4 & 18.2 & $\ldots$ \\
\hline & & & & & & & Thailand & 50.0 & 198.0 & 6.0 & 14.7 & -0.2 & 7.1 & $\ldots$ \\
\hline & & & & & & & Turkey & 318.2 & 374.1 & 38.0 & 38.0 & 0.0 & 28.0 & 9.1 \\
\hline \multicolumn{15}{|c|}{ Source: IMF staff estimates. } \\
\hline \multicolumn{15}{|c|}{$\begin{array}{l}\text { 1/ Public assets are calculated as the difference between gross and net debt in accordance with GFSM } 2014 . \\
\text { 2/ External financing requirements defined as current account deficit plus short-term total external debt. } \\
\text { 3/ Spreads are calculated as per MAC DSA guidelines. }\end{array}$} \\
\hline
\end{tabular}

\footnotetext{
1 See Schaechter and others (2011) for more details.
} 
Table 3. Debt Burden Indicators under Baseline and Stress Tests

(In percent GDP, unless otherwise indicated)

\begin{tabular}{|c|c|c|c|c|c|c|c|c|c|c|c|c|c|c|c|}
\hline \multicolumn{8}{|c|}{ Advanced Economies } & \multicolumn{8}{|c|}{ Emerging Markets } \\
\hline \multicolumn{8}{|c|}{ State of Debt Burden Indicators } & \multicolumn{8}{|c|}{ State of Debt Burden Indicators } \\
\hline & \multicolumn{2}{|c|}{$\begin{array}{l}\text { Peak debt level } \\
\text { during projection } \\
\text { period }\end{array}$} & \multirow{2}{*}{ 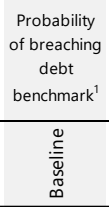 } & \multicolumn{2}{|c|}{$\begin{array}{l}\text { Peak GFN during } \\
\text { projection period }\end{array}$} & \multicolumn{2}{|c|}{$\begin{array}{l}\text { Is debt trajectory } \\
\text { non-increasing? }\end{array}$} & & \multicolumn{2}{|c|}{$\begin{array}{l}\text { Peak debt level } \\
\text { during projection } \\
\text { period }\end{array}$} & \multirow{2}{*}{ 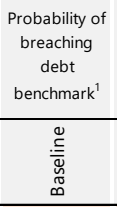 } & \multicolumn{2}{|c|}{$\begin{array}{l}\text { Peak GFN during } \\
\text { projection period }\end{array}$} & \multicolumn{2}{|c|}{$\begin{array}{l}\text { Is debt trajectory } \\
\text { non-increasing? }\end{array}$} \\
\hline 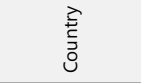 & 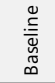 & 岕 & & $\begin{array}{l}\stackrel{\mathscr{\Xi}}{0} \\
\stackrel{్}{\Phi} \\
\infty\end{array}$ & 岕 & 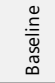 & 岕 & 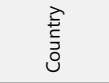 & 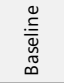 & 岕 & & 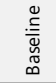 & 岕 & 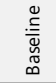 & 岕 \\
\hline Australia & 43.5 & 46.7 & 0.0 & 5.8 & 6.4 & Yes & Yes & Algeria & 11.6 & 31.7 & 1.0 & 6.2 & 12.7 & Yes & No \\
\hline Canada & 90.5 & 100.4 & 61.0 & 19.8 & 24.8 & Yes & Yes & Argentina & 53.4 & 90.8 & 27.0 & 14.7 & 23.8 & No & No \\
\hline France & 97.1 & 120.5 & 73.0 & 8.8 & 27.5 & Yes & Yes & Brazil & 86.5 & 111.3 & 84.0 & 24.3 & 32.2 & No & No \\
\hline Germany & 65.8 & 70.1 & 3.0 & 13.1 & 16.3 & Yes & Yes & China & 44.1 & 69.4 & 20.0 & 12.9 & 35.3 & No & No \\
\hline Israel & 64.5 & 75.9 & 17.0 & 10.1 & 18.4 & No & No & Colombia & 46.3 & 68.2 & 4.0 & 4.8 & 9.8 & Yes & Yes \\
\hline Italy & 132.6 & 153.8 & 100.0 & 20.9 & 33.2 & Yes & No & Egypt & 103.4 & 103.4 & 100.0 & 35.8 & 45.4 & Yes & Yes \\
\hline Japan & 239.5 & 269.8 & 100.0 & 49.9 & 61.5 & Yes & No & Indonesia & 30.5 & 41.3 & 14.0 & 5.2 & 14.9 & No & No \\
\hline Korea & 35.4 & 41.1 & 1.0 & 5.8 & 10.0 & Yes & No & Iran & 29.0 & 35.0 & 0.0 & 8.5 & 10.5 & Yes & Yes \\
\hline Netherlands & 63.5 & 88.8 & 5.0 & 8.8 & 31.0 & Yes & No & Kazakhstan & 19.4 & 30.6 & 0.0 & 4.9 & 7.8 & Yes & Yes \\
\hline Spain & 98.6 & 113.0 & 68.0 & 19.2 & 27.7 & Yes & Yes & Malaysia & 53.9 & 71.9 & 26.0 & 8.2 & 23.9 & Yes & Yes \\
\hline Sweden & 38.8 & 56.4 & 0.0 & 8.9 & 26.6 & Yes & Yes & Mexico & 53.2 & 65.8 & 8.0 & 10.4 & 13.9 & Yes & No \\
\hline United Kingdom & 99.0 & 114.9 & 22.0 & 11.1 & 22.4 & Yes & Yes & Morocco & 63.1 & 67.2 & 24.2 & 10.8 & 12.9 & Yes & Yes \\
\hline \multirow[t]{9}{*}{ United States } & 109.6 & 124.3 & 94.0 & 23.7 & 26.9 & Yes & Yes & Nigeria & 24.6 & 53.2 & 0.0 & 4.8 & 13.2 & No & No \\
\hline & & & & & & & & Pakistan & 66.6 & 75.4 & 7.0 & 25.7 & 29.0 & Yes & Yes \\
\hline & & & & & & & & Philippines & 32.6 & 38.1 & 0.0 & 4.9 & 11.3 & Yes & No \\
\hline & & & & & & & & Poland & 54.6 & 63.7 & $\ldots$ & 9.3 & 11.8 & Yes & Yes \\
\hline & & & & & & & & Russia & 18.2 & 46.6 & 0.0 & 3.4 & 7.7 & Yes & No \\
\hline & & & & & & & & Saudi Arabia & 26.4 & 45.4 & 6.9 & 10.0 & 14.1 & No & No \\
\hline & & & & & & & & South Africa & 54.5 & 71.1 & 4.0 & 11.2 & 25.0 & Yes & No \\
\hline & & & & & & & & Thailand & 42.6 & 69.9 & 4.0 & 8.4 & 24.9 & Yes & No \\
\hline & & & & & & & & Turkey & 31.6 & 38.9 & 6.0 & 6.9 & 16.3 & Yes & No \\
\hline
\end{tabular}

1/ From IMF (2016), indicator reflects the probability that debt level exceeds the indicative debt benchmark at the end of the projection period.

Table 4. Fiscal Adjustment

(In percent GDP, unless otherwise indicated)

\begin{tabular}{|c|c|c|c|c|c|c|c|}
\hline \multicolumn{4}{|c|}{ Advanced Economies } & \multicolumn{4}{|c|}{ Emerging Markets } \\
\hline & \multicolumn{2}{|c|}{$\begin{array}{c}\text { Assumed medium term } \\
\text { adjustment }\end{array}$} & \multirow{2}{*}{ 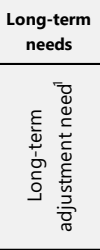 } & & \multicolumn{2}{|c|}{$\begin{array}{l}\text { Assumed medium term } \\
\text { adjustment }\end{array}$} & \multirow{2}{*}{ 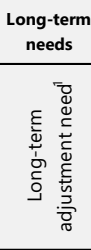 } \\
\hline $\begin{array}{l}\text { Dे } \\
\text { 志 } \\
0\end{array}$ & 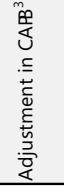 & 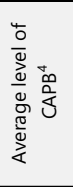 & & 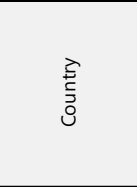 & 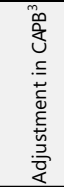 & 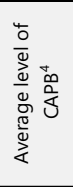 & \\
\hline Australia & 2.2 & 1.1 & 4.8 & Algeria & 12.3 & 0.9 & $\ldots$ \\
\hline Canada & 0.6 & -1.5 & 3.6 & Argentina & 2.2 & -4.5 & 6.3 \\
\hline France & 1.9 & 0.5 & 1.6 & Brazil & 1.6 & 0.3 & 15.0 \\
\hline Germany & 0.4 & 1.9 & 5.8 & China & -0.3 & -3.3 & 6.8 \\
\hline Israel & 0.0 & -0.3 & 3.1 & Colombia & 1.9 & 2.5 & 2.0 \\
\hline Italy & 1.5 & 3.7 & 5.7 & Egypt & 4.8 & -3.6 & 1.0 \\
\hline Japan & 1.7 & -2.0 & 5.3 & Indonesia & 0.5 & -0.8 & 1.5 \\
\hline Korea & 1.3 & 1.1 & 10.1 & Iran & 2.3 & -4.7 & $\ldots$ \\
\hline Netherlands & 0.4 & 0.8 & 7.3 & Kazakhstan & 5.2 & -1.1 & $\ldots$ \\
\hline Spain & 0.1 & 0.0 & 5.2 & Malaysia & 1.5 & 0.2 & 7.3 \\
\hline Sweden & 1.5 & 0.5 & 0.9 & Mexico & 1.9 & 0.9 & 3.3 \\
\hline United Kingdom & 1.8 & 0.7 & 5.7 & Morocco & 1.6 & -0.5 & 5.8 \\
\hline \multirow[t]{9}{*}{ United States } & 0.1 & -3.7 & 8.7 & Nigeria & 1.1 & -1.5 & $\ldots$ \\
\hline & & & & Pakistan & 1.0 & 0.6 & $\ldots$ \\
\hline & & & & Philippines & -0.2 & -0.3 & 1.3 \\
\hline & & & & Poland & 0.9 & -0.6 & $\ldots$ \\
\hline & & & & Russia & 2.2 & 0.2 & 6.0 \\
\hline & & & & Saudi Arabia 2/ & 14.4 & -30.8 & $\ldots$ \\
\hline & & & & South Africa & 1.2 & 1.2 & 3.2 \\
\hline & & & & Thailand & 0.4 & 1.8 & 7.8 \\
\hline & & & & Turkey & 0.9 & 1.0 & 4.6 \\
\hline \multicolumn{8}{|c|}{ Source: IMF staff estimates. } \\
\hline \multicolumn{8}{|c|}{ 1/ Long-term adjustment updated as of February 2018. See Ahuja and others (2017) for details. } \\
\hline \multicolumn{8}{|c|}{ 2/ Figures correspond to the non-oil primary balance as a percent of non-oil GDP. } \\
\hline \multicolumn{8}{|c|}{ 3/ Average cyclically-adjusted primary fiscal adjustment over any three years during the projection horizon. } \\
\hline
\end{tabular}




\section{Box 3. Fiscal Space and Long-Term Demographic Pressures}

Long-term demographic trends will place public finances of many countries under pressure. Without reforms, outlays on age-related programs are expected to increase by 9 and 11 percentage points of GDP in more and less developed countries, respectively, between now and 2100 (Clements and others, 2015). Such spending increases could lead to unsustainable public finances. In addition to aging, population decline could reduce economic growth and-if not accompanied by a commensurate reduction in interest ratesput further strain on public finances. In many cases, the brunt of the demographic shift will only be felt after 2030. As an example, the world's old age dependency ratio-the ratio of older dependents to the working age population -is expected to increase by 5 percentage points between 2015 and 2030 and 20 percentage points between 2030 and 2100 (United Nations, 2017). Thus, the assessment of fiscal space should consider the full spectrum of demographic pressures in the long-term, i.e. beyond the 2030s.

The current framework for assessing fiscal space incorporates the fiscal costs associated with aging. The second stage of the framework includes an indicator that assesses the required fiscal adjustment needs based on expected demographic pressures over the long term. The indicator measures the primary balance required after staff's forecast horizon (year $t+6$ ) in order to ensure that the debt is sustainable and the government's intertemporal budget constraint is satisfied in the very long run (i.e., after 2052). Intuitively, countries with a higher increase in age-related spending will need to implement bigger adjustments to their primary balance. The benefit of this indicator is that it takes a long view and, thus, captures the fiscal costs of aging irrespective of whether the current population is relatively young or old. Country teams can also complement this indicator with additional analyses and tools (see e.g., IMF, 2016e).

\section{Simulations}

21. Once a sense of fiscal space emerged from this sifter-like approach, simulations of discretionary policy offered a cross-check before teams made their final assessments. The simulations featured two standardized temporary fiscal expansion scenarios relative to the baseline, with alternative sets of assumptions about multipliers and risk premia (Annex I). The first scenario represented a credible, high-impact stimulus combining a good policy package and benevolent market reactions; while the second scenario reflected the opposite. In that sense, they reflected "upside" and "downside" scenarios, respectively. The debt-growth tradeoff of the fiscal expansions was evaluated under these two scenarios. This was determined, inter alia, by the initial state of the economy, including the output gap, investment efficiency, the degree of monetary accommodation, the interest rate-growth differential, and policy credibility. Country teams used their judgment about which of the two scenarios was most likely to apply given the conjunctural position of the economy, based on initial conditions like the cyclical position, the existing debt level, the outlook for financing, monetary policy settings, and the credibility of policy frameworks. 


\section{B. What Did We Learn About Fiscal Space in the Global Conjuncture?}

\section{Pilot Results}

22. Overall, the assessments showed that there is at least some fiscal space in most pilot countries. 6 countries were found to have substantial, 17 some, and 11 limited fiscal space, after taking fiscal rules into account (Table 5). For three countries, fiscal rules were binding, such that abstracting from them, the assessment would have corresponded to some rather than limited fiscal space. The assessments-without fiscal rules-were reached based on the results of the sifting technique discussed in section A. This is illustrated in Figure 1 and elaborated in Annex II.

Table 5. Fiscal Space Assessments: Pilot Results (2016/17)**

\begin{tabular}{ccc}
\hline Limited & Some & Substantial \\
\hline Argentina & Algeria & Australia \\
Brazil & Canada & Germany \\
Egypt & China & Kazakhstan \\
France* & Colombia & Korea \\
Italy & Indonesia & Netherlands \\
Malaysia* & Iran & Sweden \\
Nigeria & Israel & \\
Pakistan & Japan & \\
Poland* & Mexico & \\
South Africa & Morocco & \\
Spain & Philippines & \\
& Russia & \\
& Saudi Arabia & \\
& Thailand & \\
& Turkey & \\
& United Kingdom & \\
& United States
\end{tabular}

*The assessment without rules suggested some fiscal space.

** See footnote 1 on page 14 


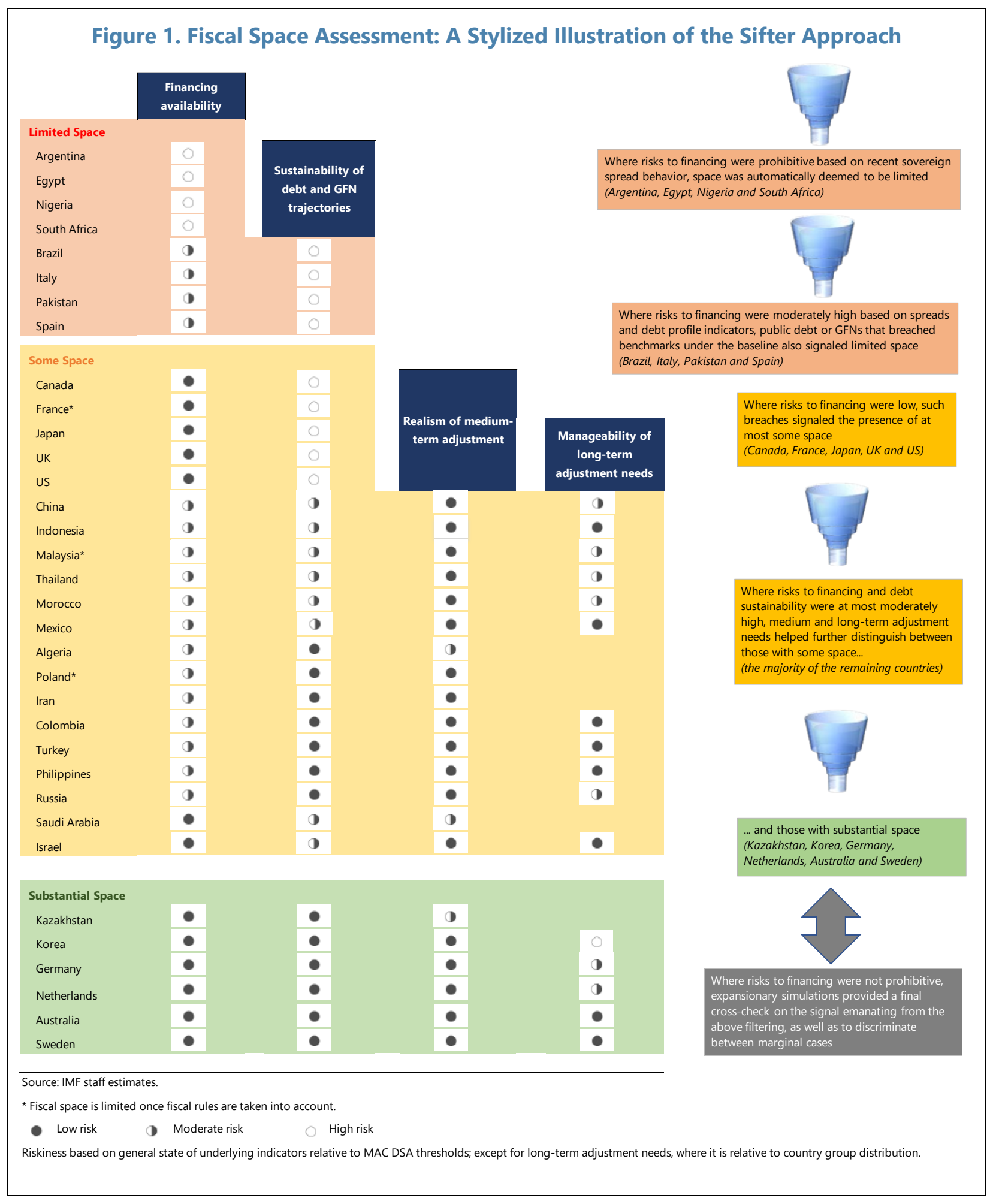

23. Viewed together, the pilots yielded several high-level insights about fiscal space in the current global conjuncture and confirmed the importance of institutional factors

(Figures 2, 3, and 4): 
- Amount of space. Notwithstanding the rise in public debt levels since the global crisis, there is more fiscal space in the pilot countries than commonly thought-reflecting more favorable interest rate-growth differentials, easier financing conditions, lower gross financing needs, longer debt maturities, and, in emerging markets, a greater share of debt being issued in local currency. ${ }^{1}$ That is, there is, in principle, scope for near term discretionary fiscal policy action in the form of a stimulus or a more gradual pace of fiscal consolidation, if justified. However, in the current conjuncture - with narrowing or even positive output gaps, and an uncertain outlook for financing and debt dynamics - there was generally a premium on caution.

- Importance of initial position. The context mattered for the assessment of fiscal space. In particular, where the cyclical position is weak, infrastructure needs exist, spending is efficient, and monetary policy is accommodative, fiscal space could be wider than meets the eye as long as financing exists, due to the potential dynamic effects of a fiscal expansion. This is even more so if stagnation risks loom (see also Gaspar, Obstfeld and Sahay, 2016). Conversely, other things being equal, more volatile and less diversified economies have less fiscal space.

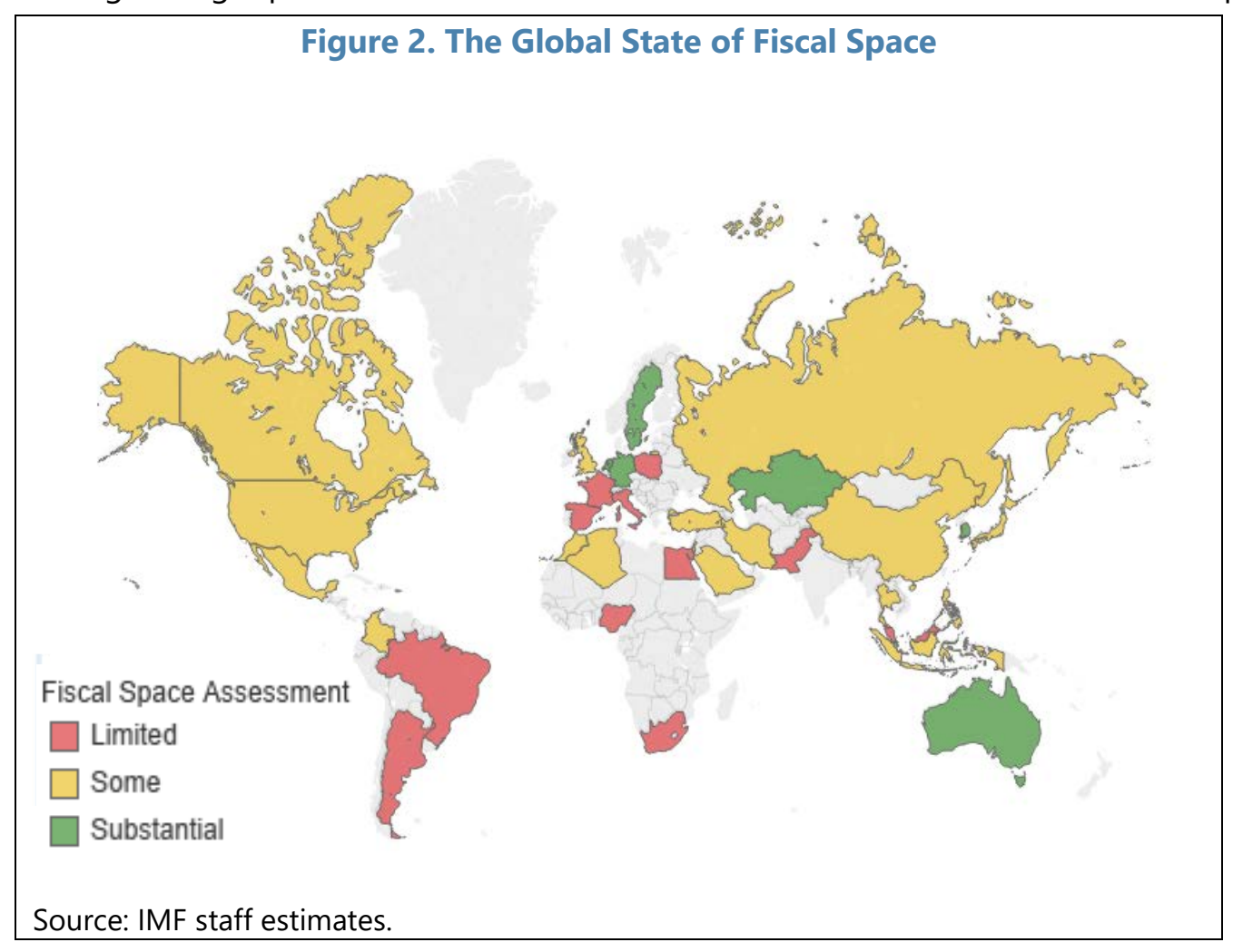

- Level of development. Generally speaking, advanced economies in the pilot had more fiscal space than emerging markets. This largely reflected more robust fiscal policy track records providing greater credibility, as well as less risky debt profiles (see also IMF, 2017a). As a result, measures to build fiscal space are not limited to revenue increases and spending decreases but may also include structural reforms to enhance credibility.

\footnotetext{
${ }^{1}$ See also IMF (2017a), Furman (2016), and OECD (2016). For a detailed analysis on the lengthening of maturities, see April 2018 Fiscal Monitor.
} 
Figure 3. Fiscal Space in the Pilots

(Weighted by nominal GDP)

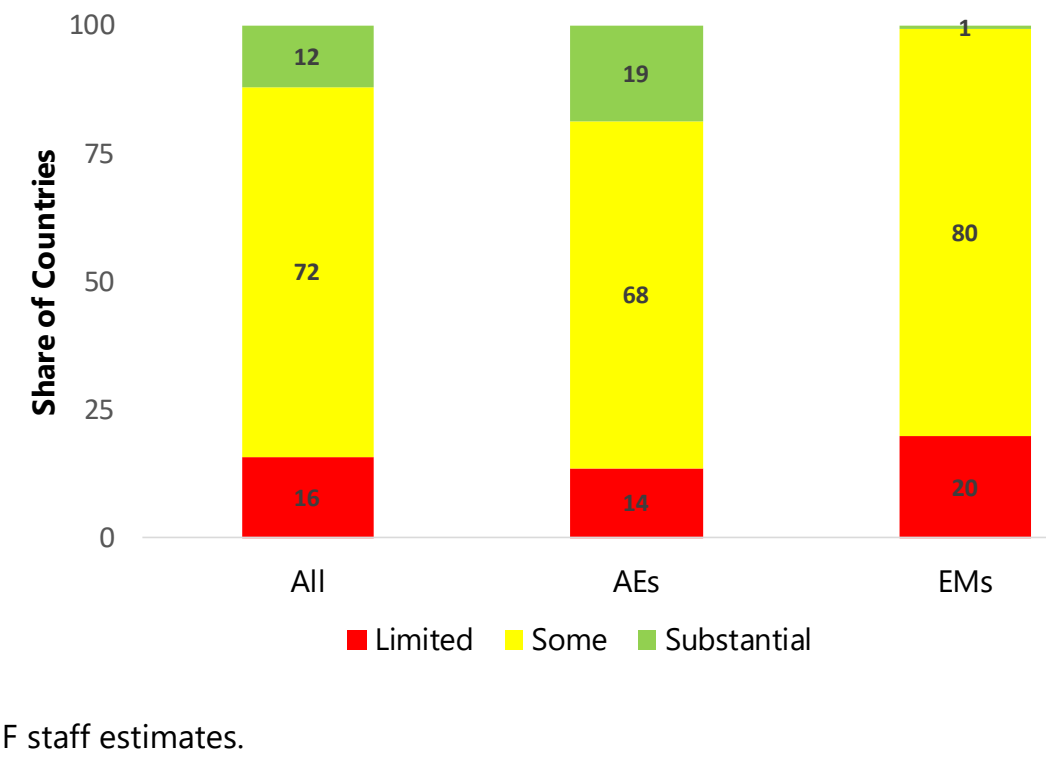

Figure 4. Fiscal Space Pilots: Evolution of Selected Indicators (Country group average)
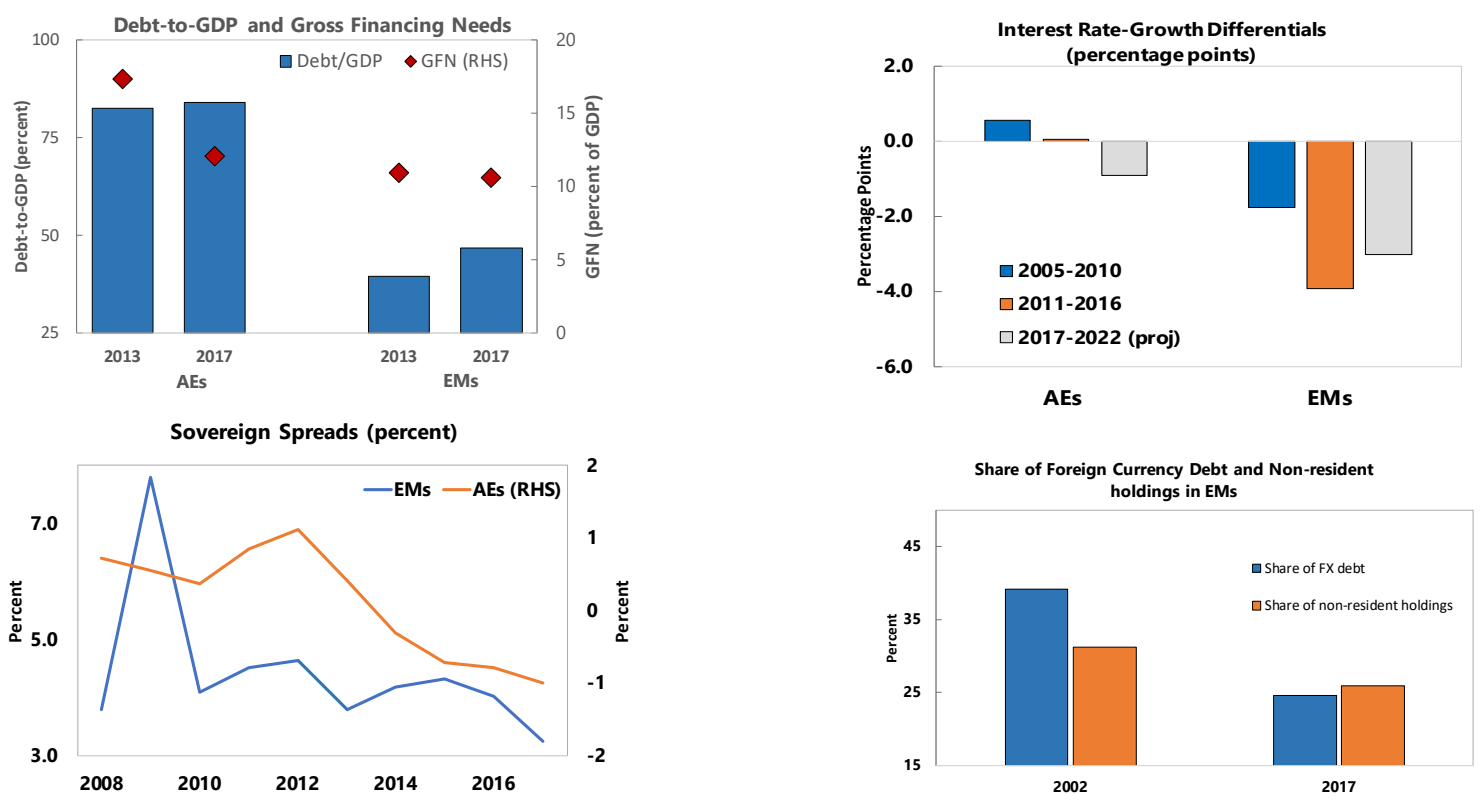

Source: IMF staff estimates. 
- Frameworks. The pilots confirmed that fiscal frameworks can help underpin fiscal space but getting their design right is key (see also Eyraud and others, 2018). For instance, some countries have fiscal rules that can play an important role in enhancing credibility, market access, and thus, fiscal space. As discussed in Box 2, it is important that these rules be well designed and calibrated, and regularly reviewed to ensure that they meet their objectives. Good rules help build and preserve fiscal space by encouraging building buffers in good times, while not unduly constraining its use when warranted.

- Balance sheets matter ${ }^{1}$. Entitlement reform in some advanced economies has helped increase fiscal space but longer-term pressures remain a significant constraint in several countries (see also IMF, 2012a and 2017a). At the same time, liquid financial assets can help provide a cushion for fiscal space, even where financing availability or debt sustainability appears relatively uncertain (see also Cottarelli and Moghadam, 2011).

\section{Stylized Facts ${ }^{2}$}

24. Emerging markets tend to have weaker financing availability indicators, which is the primary consideration for fiscal space. A few emerging market pilots were immediately determined to have limited fiscal space because they did not have access to stable and affordable financing (Figure 5). In terms of the debt profile, none of the pilot countries faced systematically high risks, such that this consideration was not decisive on its own for concluding that fiscal space was limited (Figure 6). Nevertheless. there were countries, mostly emerging markets, where market access or the debt profile appeared somewhat risky, requiring further assessment of other aspects of fiscal space such as past fiscal discipline, outstanding debt, and other liabilities.

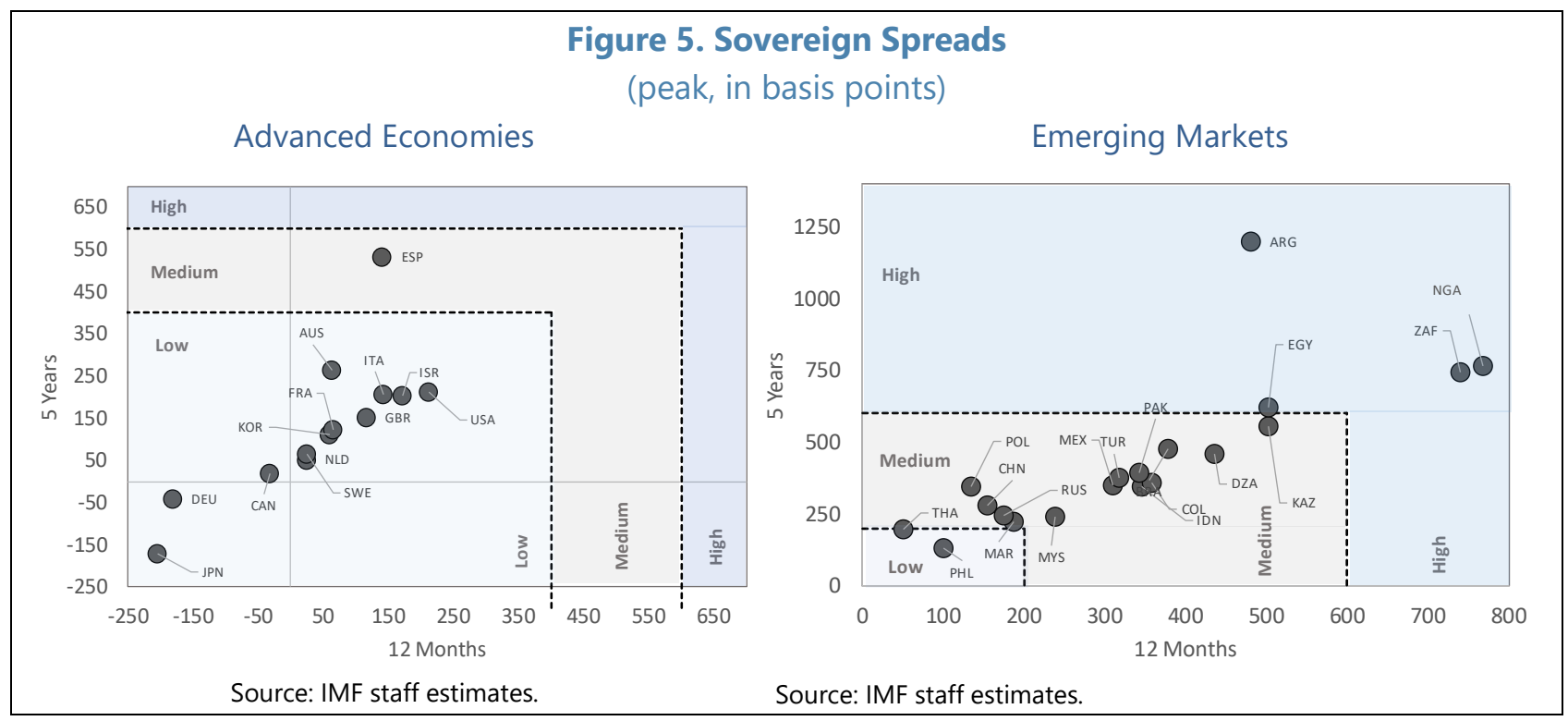

\footnotetext{
${ }^{1}$ The importance of public sector balance sheets will be discussed in detail in the October 2018 IMF Fiscal Monitor.

${ }^{2}$ Thresholds depicted in the figures of this section correspond to those used in the MAC DSA.
} 


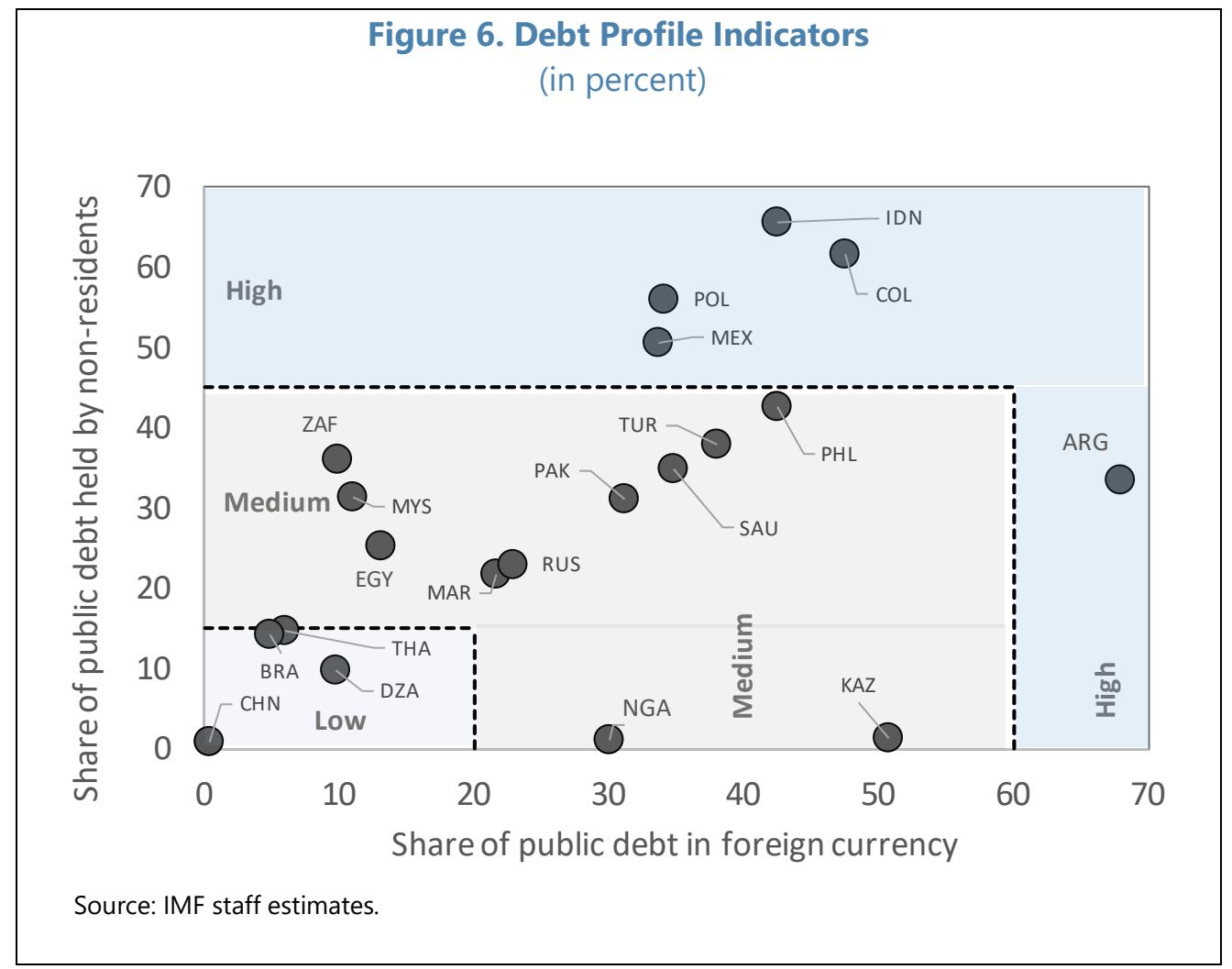

25. On the other hand, advanced economies generally have elevated levels of public debt, with half of these pilots breaching benchmarks, weighing on their fiscal space assessment. In some cases, this high debt burden also translates into high GFNs, further constraining fiscal space. Two advanced economy pilots were deemed to have limited space based on these considerations (Figures 7 and 8). Reflecting generally less favorable financing conditions, emerging markets have lower public debt levels, although these are often on an increasing trajectory. This reduces fiscal space, in particular when market access and debt profile indicators point to some financing risks, which is the case to different degrees in almost all emerging markets. Here it must be remembered that advanced economy risk benchmarks are less stringent, precisely because they tend to be able to sustain higher debt levels, in some cases due to reserve currency status.

\section{In some cases, while debt and financing needs seem manageable, large medium-} term adjustment needs constrain fiscal space. In particular, some countries hit by permanently lower oil prices face challenging adjustment needs to keep the fiscal position sustainable (Figure 9). Nevertheless, in a few of the pilots, favorable starting points in terms of debt and GFNs_often augmented by the availability of sizeable financial assets-provides for at least some fiscal space that can be used for more gradual adjustments. 


\section{Figure 7. Public Debt Level ${ }^{1}$}

(percent of GDP)

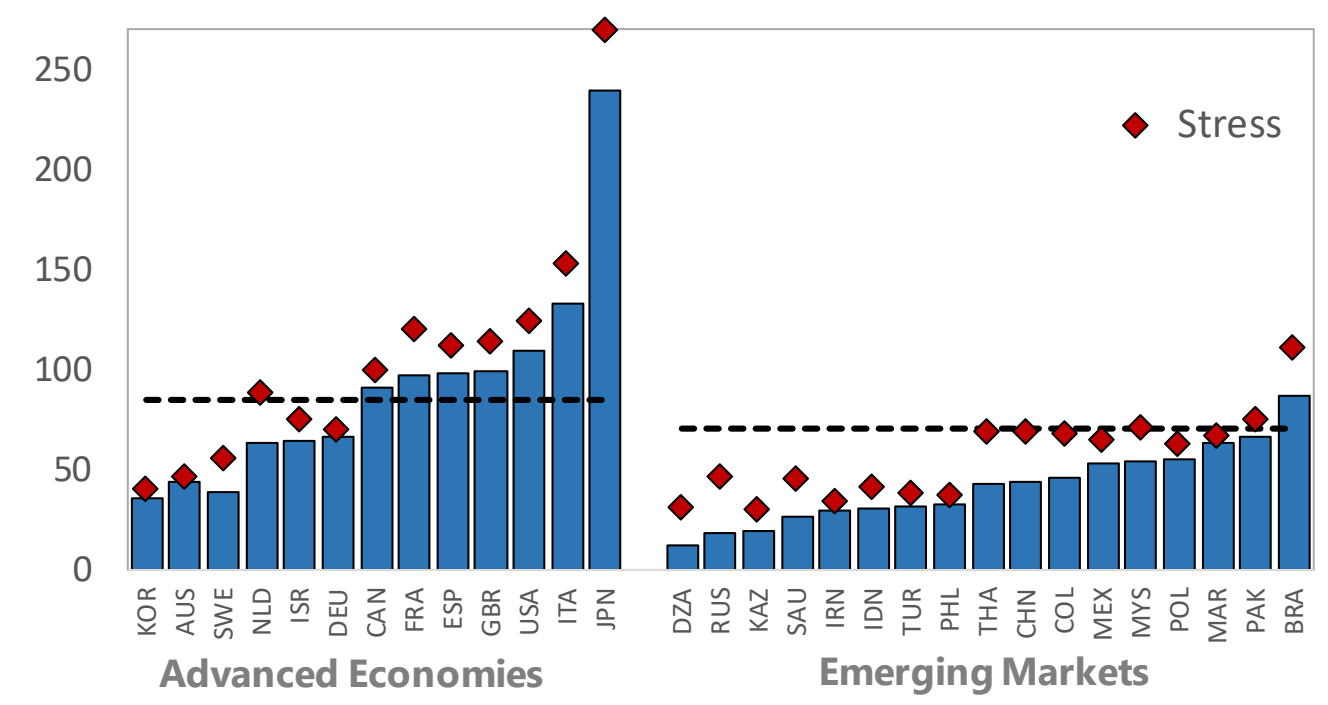

Source: IMF staff estimates.

${ }^{1}$ Figure depicts the peak public debt level during the projection period under the baseline and under the most severe shock considered in the MAC DSA.

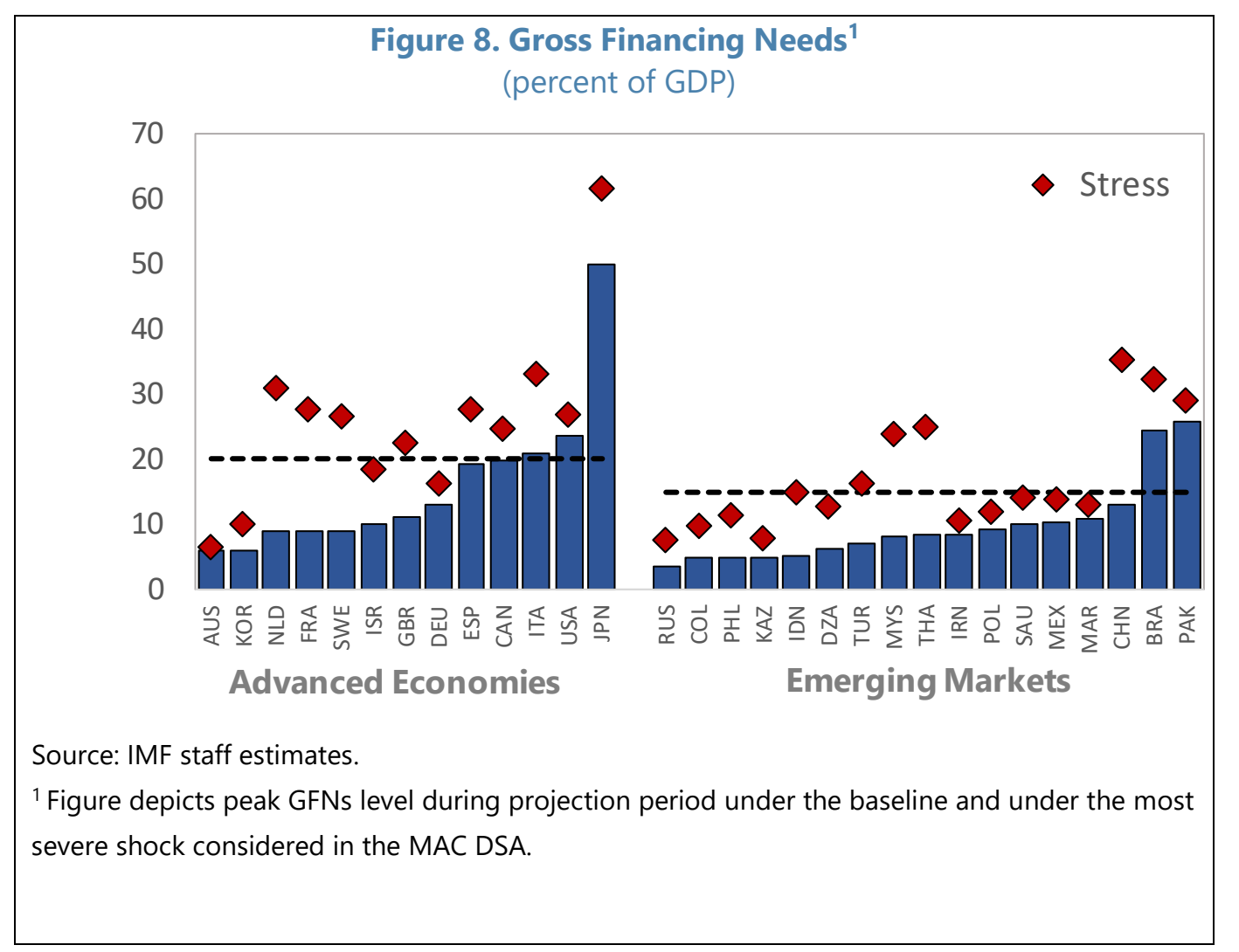




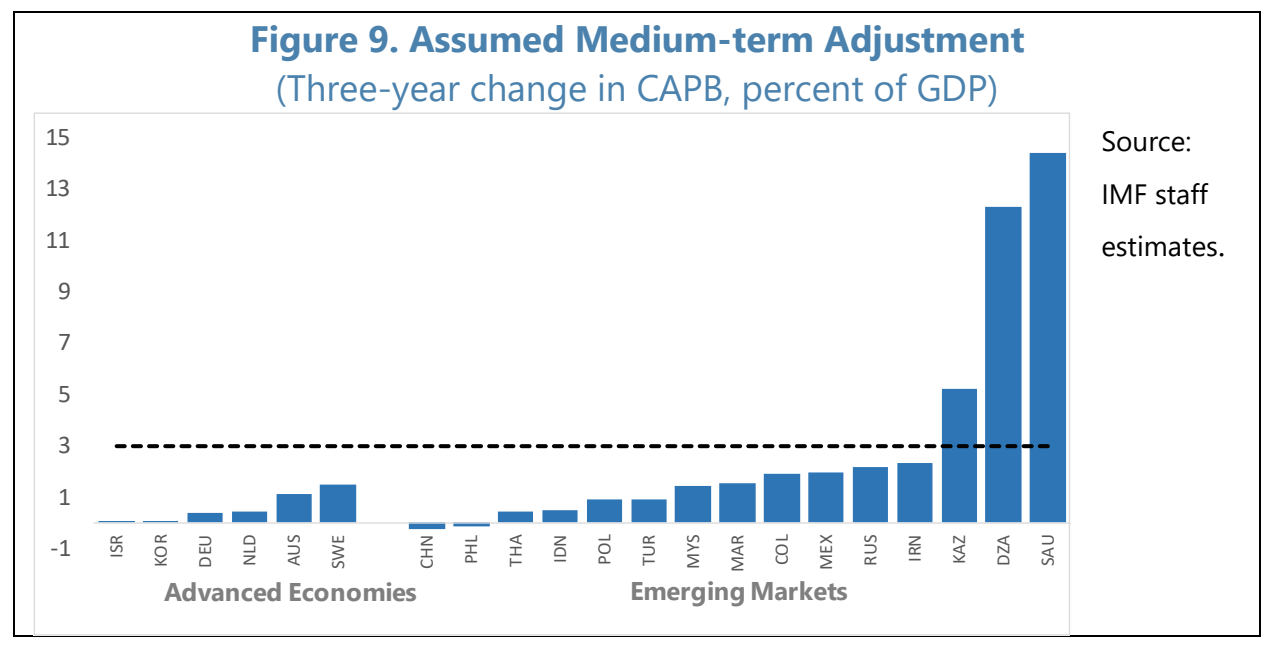

\section{Long-term demographic pressures weigh on fiscal space, especially in advanced} economies and countries with exhaustible resources. As a result, many countries face a tradeoff between addressing current cyclical and structural needs and long-term adjustment needs. One interesting case is Korea, where fiscal space is abundant by all other metrics, but impending demographic pressures are significant. Hence, even as fiscal space is substantial and the advice is to use it, the need for reforms to address long-term pressures is also emphasized (Figure 10). China is another example, where there are near-term structural needs, but demographic concerns are a constraint over the longer term.

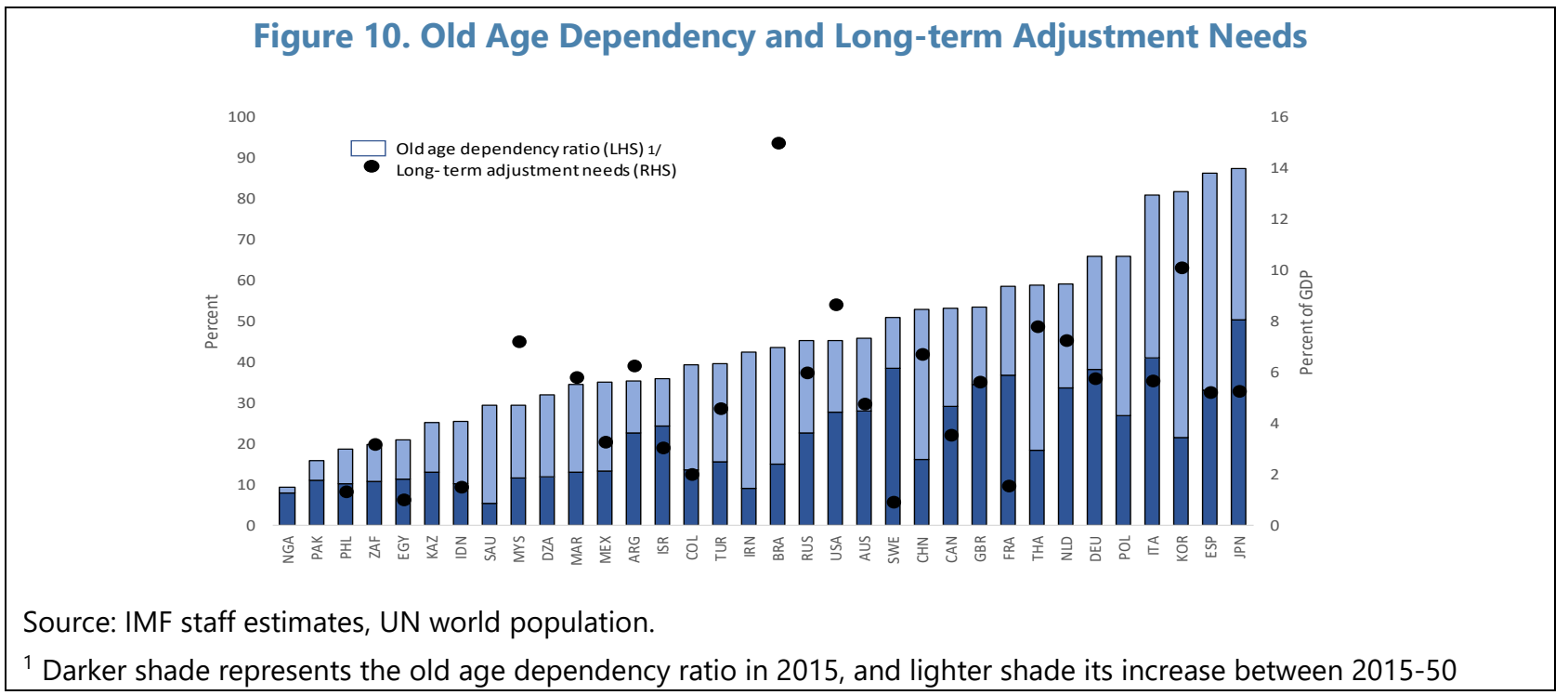


28. Where market financing is not prohibitive, the initial state of the economy and the potential dynamic impact of a looser stance can have important implications for fiscal space. The simulations run as part of the third stage helped provide a cross-check on the signal emanating from the filtering approach, as well as to discriminate between marginal cases. Overall, in the current conjuncture, the debt and gross financing dynamics for the pilots under the scenarios did not change to the extent that the conclusions from the previous analysis were materially altered. However, the analysis tended to strengthen the conclusions:

- In the upside scenario, the effect on nominal GDP was very high for several countries with limited fiscal space, in part reflecting relatively large output and infrastructure gaps. However, the worsening of debt dynamics was generally seen as unfavorable. Moreover, for many of these countries, a lack of access to finance remained the binding constraint. For countries with at least some fiscal space, the output effects were generally more muted, but still large enough to limit the increase in debt/GDP, confirming the strong position of those countries.

- In the downside scenario, the debt and growth impacts were fairly similar across countries. This confirmed the constrained ability of countries with limited fiscal space to adopt a looser fiscal stance, even if desirable from other aspects.

More generally, as discussed in Box 4, the debt-growth tradeoff of a looser fiscal stance depended on country-specific circumstances, and yielded several interesting general insights.

\section{Box 4. What Can Be Learnt from the Simulations?}

As illustrated by the significantly better results in the upside scenario, the nature and circumstances of a fiscal expansion matter for the effect on growth and debt (see figure below).

- First, the type of fiscal expansion matters. If it is directed toward measures with high multipliers such as infrastructure investment, transfers to liquidity constrained households, and government consumption, the positive growth effects will be significantly stronger.

- Second, the initial state of the economy is important. The effect of a fiscal expansion on growth and debt is much more favorable if there is a significantly negative output gap. In this context, more accommodative monetary policies, as would be expected when there is slack in the economy, also support the effects of fiscal expansion by allowing real interest rates to decline and further stimulate private demand. Moreover, as discussed in Gaspar, Obstfeld and Sahay (2016), where the counterfactual is an extended period of low growth and inflation, even if debt rises somewhat as a result of a fiscal expansion, it may be compensated by the benefits of heading off this more severe negative macroeconomic outcome.

- Third, the effect of fiscal policies on financial conditions must be considered, as financial markets will likely react better to well designed and sustainable policies, helping contain risk premia and interest rates. 


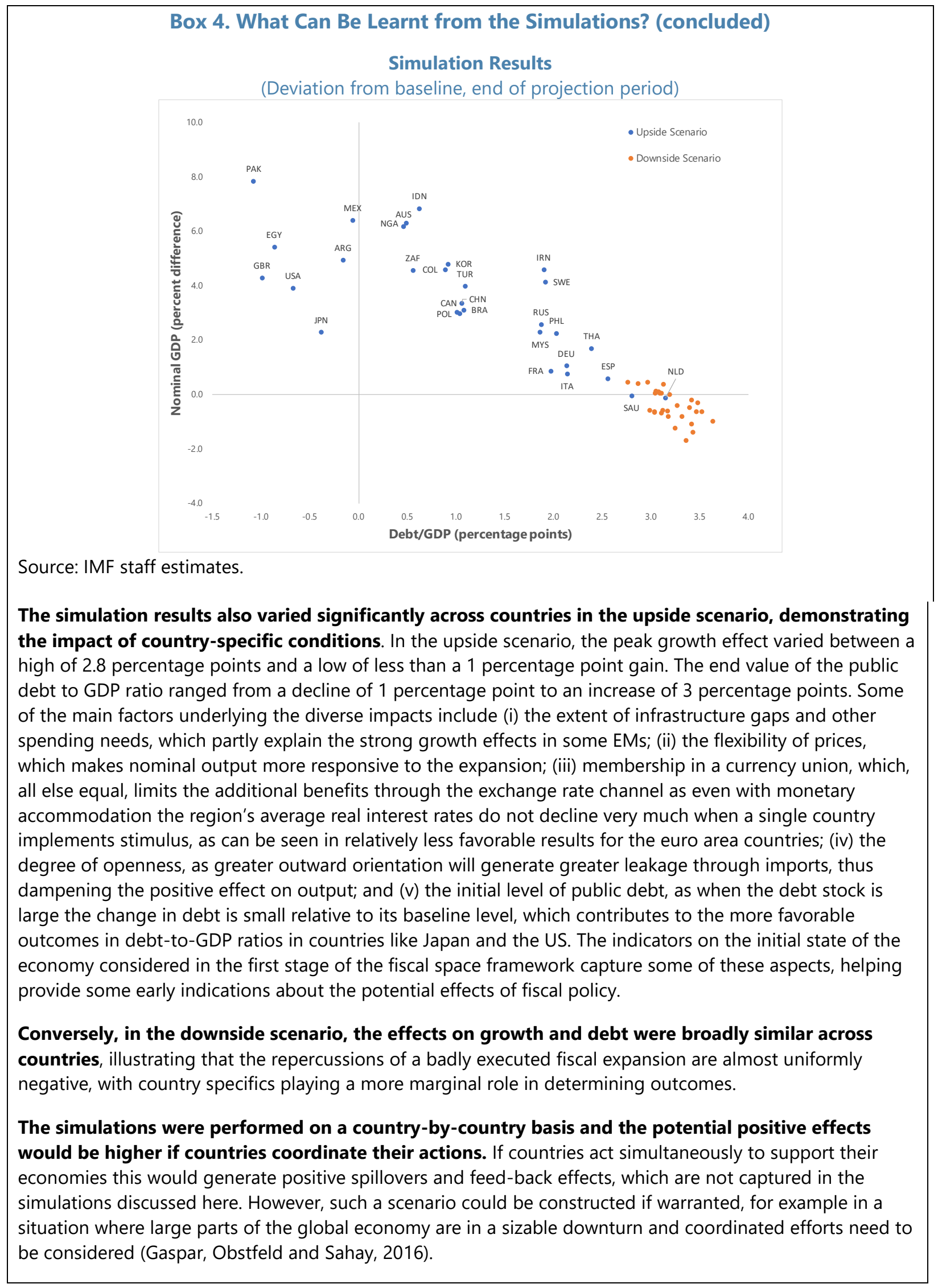




\section{Fiscal Policy}

\section{The fiscal space assessments strengthened the policy recommendations and}

discussion. Fund advice on the use of fiscal space varied across countries, reflecting the distinction between its existence and use. While this was not the primary objective of the framework, the amount of fiscal space had direct implications for the fiscal policy advice. Where there was limited space, there was no room for a looser fiscal policy stance, and any discretionary measures had to be budget neutral. In some cases, consolidation was needed to secure fiscal sustainability. For countries with relatively constrained fiscal space but where the domestic economy was weak or vulnerable, the appropriate pace of consolidation was a key policy question (see also IMF, 2012a and 2017a). On the other hand, if there was at least some fiscal space, the policy options were expanded, and depending on the specific circumstances, the recommendation was for fiscal policy to support the economy in case of a downturn, facilitate growth enhancing structural reforms, or increase public investment.

30. Having fiscal space does not necessarily mean it is optimal to use it, and teams took many other considerations into account, including the state of the economy and the expected quality of fiscal measures. Overall, the advice tended to be fairly cautious, reflecting a general need to replenish buffers and rebuild fiscal space amid generally strong cyclical conditions (Figure 11):

- In the countries with substantial fiscal space, it was recommended to be used for a gradual fiscal consolidation (Kazakhstan, Australia), to support the recovery (Korea) while also raising infrastructure spending (Australia) or supporting structural reform (Korea), and for long-term growth enhancing spending or tax cuts (Germany, Netherlands). In Sweden, a relatively gradual decline in the fiscal surplus to its medium-term target was recommended given robust economic prospects.

- In the countries with some fiscal space, staff advised it could be used to target a more gradual fiscal adjustment in the baseline (Algeria, Iran, Saudi Arabia, Indonesia) or as part of contingency planning (the United Kingdom), to postpone fiscal tightening if downside risks materialize (Russia), to provide a temporary stimulus to cushion the impact of negative shocks (Turkey), for growth-enhancing public investment (Philippines, Thailand), to secure a cyclical inclusive recovery (Canada), for additional peace expenditure (Colombia), to avoid a near-term scheduled withdrawal of fiscal stimulus (Japan), or to support structural reforms (China, Indonesia). In other cases, it was recommended that fiscal space be protected or bolstered (Israel, Morocco, Russia, and the United States).

- In the countries with limited fiscal space, the ability to use discretionary fiscal policy was constrained and the advice focused on building buffers through timely fiscal consolidation (Argentina, Brazil, Egypt, Italy, France, Malaysia, Nigeria, Pakistan, Poland, South Africa, and Spain). 
Figure 11. Fiscal Advice in the Pilots ${ }^{1}$

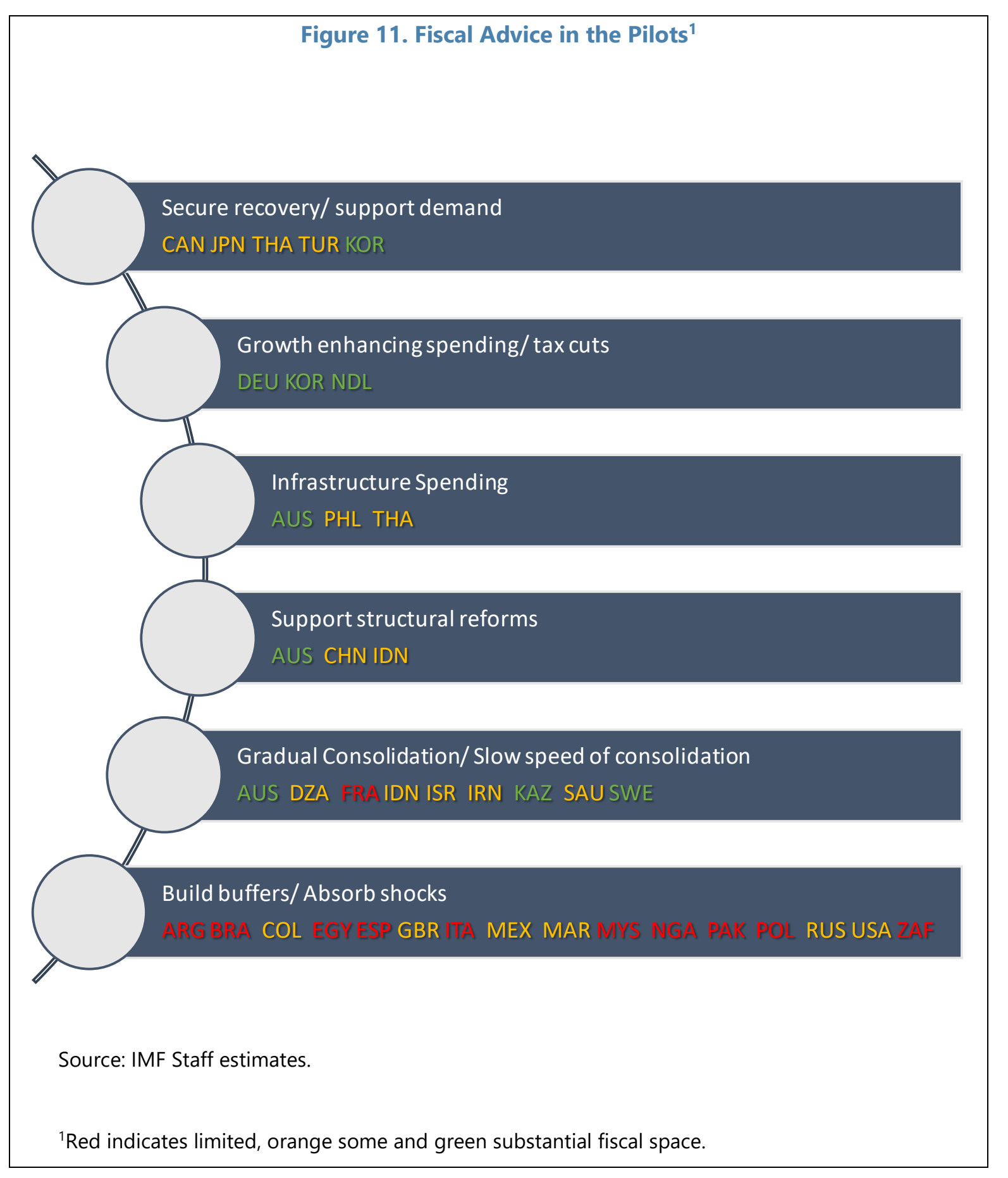




\section{Were the Objectives of the Pilot Met?}

31. The fiscal space pilot had a number of objectives. The intention was to provide a wellmotivated sense of how much fiscal space exists in different countries and to support discussions on the appropriate fiscal stance. With that in mind, the framework was designed to: (i) provide a common language and set of metrics for discussing fiscal space; (ii) facilitate qualitative assessments of fiscal space based on commonly available data-while still leaving scope for desk judgment where necessary; (iii) ensure a pointed and clear discussion of fiscal space in country reports; (iv) provide insights for policy formulation and engagement with the authorities in discussions about fiscal space; and ( $v$ ) support evidence-based and consistent internal review of country documents. It was also hoped that the pilot would be implemented in a cost-effective way.

32. The framework generally worked well across the various pilot countries, generating fiscal space assessments that were broadly consistent with its underlying logic and indicators. While differences in the assessment across countries were clearly explainable within the framework, desk judgment still played a critical role in framing the analysis in a countryspecific context. As a result, the assessments contributed to delivering a well-founded sense of the extent of fiscal space in major economies. The pilots also revealed the importance of modifying the framework to better capture some of the specificities of commodity producers, as further discussed in the next section.

\section{This consistency was the result of assessments being guided by a multi-dimensional} analytical approach, while still leaving scope for desk judgment in making the final call. As illustrated in section $B$, the framework provided a structured approach for assessing fiscal space in a way that is comparable across countries-based on a uniform definition and taxonomy, as well as a common set of considerations and metrics. Indicators based on the DSA and other readily available data helped ensure consistency, and country teams formulated and motivated a bottom-line assessment of whether the country had limited, some or substantial fiscal space (Annex II). The clarity of the assessments was further strengthened as the framework explicitly requires that the existence of fiscal space is separated from its use. Importantly, this prevented a hitherto natural inclination to jump directly to the use of fiscal space, while skipping the more basic question of whether there is fiscal space to begin with.

\section{Use of the framework helped strengthen the discussion of fiscal space in Article IV}

Staff Reports. A comparison with Staff Reports in 2015 and 2016 for the pilots showed that tangible progress has been made in explicitly quantifying and discussing the amount of fiscal space. While most past Reports did refer to fiscal space, more than 10 percent did not, and it was often not clear what was meant by fiscal space as there was no common or clear definition. Perhaps more importantly in three-fourths of the cases, fiscal space was treated in the context of the need to create space rather than its availability, i.e., without explicitly presenting the starting point in terms of available fiscal space. In only one-sixth of the Reports was fiscal space quantified 
in some way, and only one-third of these did so based on some measurable indicators (relying mostly on the debt level alone).

\section{Moreover, the framework fostered a tighter link between the assessed fiscal space} and the fiscal policy advice, while supporting the dialogue with authorities. In the past, when fiscal space was discussed, it often did not appear to be explicitly tied to the fiscal policy discussion. In the pilot, the fiscal space assessment helped further substantiate the advice for many countries, and coincided with some change in the recommendations compared to the previous cycle in one-third of the cases. For example, calls for the pace of consolidation to be more gradual, a temporary expansion to support growth, or more aggressive growth-enhancing measures were consistent with cases where countries had at least some fiscal space. At the other end of the spectrum, the existence of only limited fiscal space helped provide stronger justification for building larger fiscal buffers.

\section{Assessing fiscal space with and without rules created relatively little tension in the} current conjuncture. In most cases, there was no apparent difference between the assessments with and without taking fiscal rules into account. In only three countries were fiscal rules binding, resulting in an assessment of limited rather than some fiscal space, but given the prevailing economic circumstances the rule remained an appropriate guide for fiscal policy. In these Staff Reports, it was noted that fiscal space was constrained by the fiscal rules but that there was some fiscal space for discretionary actions, should it be needed in the face of shocks. If anything, discussions were enriched by the fiscal space assessments as, in the past, rules were mostly taken as given, which tended to constrain discussions of their design and the desirable fiscal stance. In the case of Malaysia, the design of the rule and possible reforms were also discussed.

\section{Internally, the framework supported evidence-based review of country documents.}

All the pilot countries' Article IV documents were reviewed specifically with respect to fiscal space, to ensure that the framework was appropriately and consistently implemented across countries. Spelling out underlying considerations and bottom-lines, while maintaining a clear distinction between existence and use, gave fiscal space a more central place in internal discussions. In these discussions, the assessments were reviewed within a cross-country framework, which helped sharpen justifications, and sometimes contributed to moving the needle on the assessment. The framework also promoted a forward-looking assessment of fiscal space, including in a dynamic setting with respect to the risk-return trade-off associated with potential fiscal expansion given the conjunctural position of the economy.

\section{The resource burden was moderate compared to other recent initiatives. By} construction, the framework was relatively easy for country teams to apply, and implementation therefore required relatively few resources, especially for area departments. The majority of indicators for the various stages were automatically provided to country teams by functional departments. As a result, teams had to provide only limited quantitative input and could focus on the actual assessment of fiscal space. There was also a clearly-communicated and common expectation for the coverage of fiscal space in Article IV consultation documents. Overall, the fiscal space pilot compared favorably with most other pilots in terms of budgetary resources 
expended. Some technical refinements of the framework could also be considered to further simplify implementation for country teams, which will require some one-time fixed costs.

Nonetheless, broader roll-out of this tool will have resource costs, given data constraints and the need for a more tailored approach for specific groups of countries (see next section); resource reallocation options will be explored. For country teams new to the exercise, roll-out will also require some investment to apply the framework for the first time.

\section{At the same time, the pilot suggested scope for some technical refinements of the}

fiscal space framework. Some of these areas were already recognized at the outset in the 2016 Board paper, notably:

- Behavior of risk premia. The degree of access to finance is inherently difficult to pin down. It is subject to surprises and non-linear reactions to developments. Currently, the framework incorporates some of this uncertainty in the form of the upside and downside simulation scenarios in the third stage. Notwithstanding empirical challenges, where these are available, there may be scope to also include some indicators on market access sensitivity in setting the context as part of the first stage, such as: (i) traditional indicators of exposure to global conditions (e.g., estimated exchange rate over-valuation), (ii) sensitivity of interest rates to global conditions (e.g., VIX, US 10 year rate, exchange rate volatility); and (iii) the volatility of sovereign spreads and their correlation with economic news and bank spreads.

- Differentiated thresholds and time horizons. The framework currently relies on MAC DSA thresholds, which only differentiate between advanced and emerging economies. During the pilot phase, however, the analysis of debt and gross financing needs illustrated that the appropriate thresholds to apply remains a challenge and varies with country circumstances (e.g., having a reserve currency, being subject to more geopolitical uncertainty or volatile terms of trade, or possessing strong and credible fiscal institutions). The appropriate threshold for a particular type of economy is thus an aspect that could be brought out more explicitly in the framework, in line with the planned MAC DSA update. Similarly, the MAC DSA time horizon of five years may sometimes be too short to capture fiscal pressures materializing over a somewhat more distant but still relevant time period, suggesting a longer horizon for some indicators may be desirable, in addition to the existing indicator of longterm fiscal pressures. The MAC DSA update also plans to examine this issue.

- Strengthened scenario analysis. In the third stage, more customized scenarios featuring a different scale and composition of discretionary fiscal actions could be used in addition to the standardized simulations, when warranted. This would help to better reflect country specificities, provide additional power to determine a bottom-line when indicators are mixed, and more closely link the assessment to the policy advice. For countries not covered by DSGE models run by the Research Department (RES), teams could instead rely on customized scenarios available as part of the standard debt sustainability frameworks.

Other areas requiring more extensive augmentation became apparent as the implementation progressed. Overall, the pilots confirmed that it is crucial to assess fiscal space in a countryspecific context that accounts for the country's exposure to shocks, economic structure and level 
of development. The next section discusses these and proposes possible extensions of the framework to address them.

\section{EXTENDING THE FRAMEWORK TO STRENGTHEN FISCAL SPACE ANALYSIS}

\section{A. Low-income Countries}

40. Low-income countries (LICs) display some characteristics that are typically not shared by emerging and advanced economies. LICs tend to be more vulnerable to shocks. As their economic structure is less diversified, they are more sensitive to supply or terms of trade shocks affecting their dominant sectors. Weaker infrastructure also makes them more vulnerable to natural disasters. Related to this, LICs are much more susceptible to structural breaks. All of this suggests the need for a larger "safety margin" in assessing fiscal buffers and debt sustainability. ${ }^{1}$ Moreover, assessing the cyclical position in LICs can be very challenging and fraught with uncertainty. At the same time, LICS tend to have a smaller capital base, implying a potentially higher growth dividend from capital investment (IMF, 2012b). While the return on capital is often held back by lower public investment management capacity in LICs (IMF, 2012b; Gupta and others, 2014), the growth dividend nevertheless tends to be higher and, hence, there is more potential room for fiscal policy to create space.

\section{The difference in the way that LICs are financed also creates challenges for} identifying fiscal space. A majority of LICs have no or limited market access but rely on official financing and are very often financially constrained. Moreover, the reliance on official financing introduces a different relationship between fiscal policies, debt sustainability and the availability of financing. First, there is a two-way relationship between fiscal policy and the availability of financing. While donors would most often like to see responsible fiscal policies in order to disburse, fiscal policies tend to be tightly constrained by the availability of official financing. Secondly, unlike economies relying on market financing, high risk debt indicators do not necessarily signal high financing risk. Concessional financing does not always reflect sustainability concerns as developmental objectives may take precedence, and access to grants and highly concessional borrowing might be retained or even increase when debt risk indicators point to high risk levels (for instance, some creditors shift their financing mix more toward grants).

42. As a consequence, for the significant majority of LICs that are largely dependent on donor aid for financing, the current indicator-based fiscal space framework cannot be applied. With the availability of financing to a large extent determined by non-quantifiable factors, an indicator-based framework is not a good fit. In these cases, the debt sustainability analysis already provides important insights into debt vulnerabilities, and whether the proposed

\footnotetext{
${ }^{1}$ The assessment of fiscal space will vary significantly depending on the uncertainties taken into account in the analysis. See Baum and others (2017).
} 
financing mix would exacerbate them. Thus, staff do not propose to extend the fiscal space framework to these countries. However, it should also be noted that to the extent that higher debt risks may shift the financing mix toward a higher average grant element without reducing the overall financing envelope, the LIC DSF risk rating does not necessarily give clear guidance on the availability of fiscal space.

\section{However, for countries that can obtain a significant amount of external market or} other non-concessional financing, the framework can be helpful, supplemented by other indicators. This could be done by applying the overall structure of the fiscal space framework, while taking into account particular characteristics of low-income countries, adjusting the choice of indicators to these characteristics and to data availability (see preliminary reflections in Box 5, which could be refined with further analysis). For countries for which the LIC DSF is used, the debt rating aggregates debt burden indicators into a signal. In some cases, the quantitative analysis on availability of financing will also need to be complemented with a qualitative assessment based on discussions with major donors.

44. The fiscal space assessment and the LIC DSF rating are complementary. The LIC DSF provides a specific risk rating based on four external debt indicators (solvency and liquidity), total public debt, stress tests, and judgment on country-specific circumstances. In general, the existing measures of fiscal space will be related to this risk rating given the centrality of debt sustainability in forming a view on the available fiscal space. Nevertheless, there could be instances where the signals from the two will be different. The underlying reasons could vary country by country. For instance, a country may have a high risk rating but still have fiscal space because additional financing at favorable terms is available for critical investment projects or to respond to external shocks. Alternatively, a country may have a low risk rating but have little fiscal space because of lack of funding at reasonable costs. In these kinds of instances, country teams will be expected to be prepared to explain these differences on a case-by-case basis. 
Box 5. Assessing Space for LICs with Market Access: Potential Additional Indicators

\section{Stage 1: Setting the Stage}

Indicators and tools to assess heightened vulnerabilities

- Incidence of natural disasters in the past

- Level of diversification (e.g., dominant product's share of total GDP or exports)

- Volatility of fiscal revenue

- Revenue ratio

- Assessment of the drivers of public debt dynamics can help identify contributions to unexpected debt changes in the past $1 /$

Growth dividend from capital spending

- Marginal impact of public investment scaling up 2/

\section{Stage 2: Financing and Debt Burden Indicators}

Is financing available?

Market financing:

- Continued access to international financial markets 3/

- The LIC DSF market financing tool can also offer a preliminary perspective on the continued availability of market financing, flagging low, medium or high risks of market financing pressures

Availability of other financing:

- Undisbursed commitments under existing facilities

- Non-market commercial borrowing over the past 12 months

State of public debt indicators

- Use of DSA stress tests to assess the impact of shocks such as contingent liabilities, volatile commodity prices and natural disasters 4/

\section{Stage 3: Expansionary Fiscal Scenarios}

- Simulation of discretionary fiscal policy experiments relative to the baseline 5 /

1/ A specific tool for this is available in the new LIC DSF. The MAC DSA automatically provides a breakdown of past contributions to debt dynamics.

2/ The new LIC DSF template also includes a tool to assess the consistency between growth and public investment assumptions. Additional available tools include the IMF's Debt-Investment-Growth model (see Buffie and others, 2012), its extension to account for natural resources (DIGNAR) (see Melina and others, 2014), the World Bank's Long-Term Growth model (see Pennings, 2017). The World Bank's country economists are also encouraged to run simulations using MFMod (see World Bank, 2015).

3/ Continued, recent and substantial public sector issuance in international markets would indicate market access. For a conceptual framework on how to assess market access and signals of loss thereof, see The Fund's Lending Framework and Sovereign Debt-Further Considerations, Box 2 and Annex III.

4/ The LIC DSF and the MAC DSA templates provide for tailored or customized scenarios.

5/ Both the LIC DSF and the MAC DSA provide tools for assessing fiscal shocks, either as a primary balance stress scenario or a fully customized scenario. 


\section{B. Commodity Producers}

45. Large endowments of natural resources complicate macroeconomic management and, consequently, the assessment of fiscal space. Natural resource endowments can be both a blessing and a curse; while providing an exceptional opportunity for economic development, they can be a source of detrimental volatility due to the unpredictable and often large and persistent shocks to commodity prices. Natural resources are also exhaustible and, in a context of large uncertainty about prices and reserves, choices must be made between creating larger buffers now for precautionary purpose and intergenerational equity or using more of the revenue generated to finance investment for future growth. Adding to the challenge, there may sometimes be a trade-off between the objectives of short and medium-term stability on the one hand, and the preferred long-term savings-investment profile on the other.

\section{The complex issue of how to use the additional fiscal space generated from resource revenue typically takes center stage in setting fiscal policies for commodity producers.}

Policy advice on macroeconomic frameworks for commodity producers often focuses on long term sustainability taking into account intergenerational equity, the need for precautionary savings, and desirable investment in physical and human capital for future growth (IMF (2012b and 2015)). The appropriate design of this framework depends on country specific circumstances, such as the durability of the natural resources, existing capital stock, demographic structure, and strength of institutions.

\section{Nevertheless, as in other cases, understanding commodity producers' near-term policy options requires assessing the existence and degree of fiscal space. The distinct} characteristics of these countries make it difficult to simply apply the general fiscal space framework without missing key considerations. Several modifications are thus proposed to capture the unique issues faced by commodity producers while keeping the framework tractable. The goal is to limit the burden on country teams while giving them flexibility to use more advanced tools— to the extent relevant-to make an assessment of fiscal space. The main considerations are:

- Accounting for the volatility of commodity prices. To this end, staff propose to add indicators of volatility to the framework, (stage 1), and make use of a DSA customized alternative scenario for assessing the effect of a large decline in commodity prices (stage 2). ${ }^{1}$

- Giving allowance for existing fiscal buffers. While the framework already takes public financial assets into account (stage 2), this may deserve further emphasis for commodity producers. Consideration needs to be given to whether reliable data on government assets exists and the extent to which these assets are available for use. Bearing these constraints in mind, teams

\footnotetext{
${ }^{1}$ See Staff Guidance Note for Public Debt Sustainability Analysis in Market Access Countries, p. 24. For LICs with market access for which the LIC DSF is still used, the new LIC DSF will include a tailored stress test for commodity producers.
} 
could assess whether the outcome of debt burden indicators would differ if available assets are considered. ${ }^{1}$

- Tailoring the debt sustainability analysis to the commodity production horizon. For countries with a very long horizon, the additional considerations in assessing fiscal space are about managing volatility and liquidity risks. However, for countries with a shorter commodity horizon, debt sustainability beyond the MAC DSA's current five-year horizon also becomes essential to the assessment. As markets may anticipate the end of resource extraction, it is furthermore harder to separate the assessment of continued market access from the use of the fiscal space. Consequently, for commodity producers with a production horizon of 15 years or less, staff suggests that the MAC DSA time horizon be extended to at least five years beyond depletion. ${ }^{2}$ This will also require explanation of the underlying assumptions about usage and associated growth effects during this period.

Reflecting these considerations, a number of additional indicators relevant to commodity producers could be added to the different stages of the fiscal space framework (Box 6).

\section{In staff's bottom-line assessment, it will be important to apply judgement and assess space with and without fiscal rules, and/or intergenerational equity considerations.} The framework sets out that the bottom-line assessment should be made both with and without taking fiscal rules into account. When assessing fiscal space under the constraint of fiscal rules and/or intergenerational equity considerations, teams can where relevant, also take into account the need to save for future generations based, for example, on a permanent-income-hypothesis analysis that explicitly considers the exhaustibility of natural resources. While such a constrained assessment is more about the use of fiscal space than its availability per se, it may be a useful concept as discussion of fiscal policy in commodity producing countries is often formulated in such terms. From a pragmatic perspective, it is difficult to embed into the framework a single indicator capturing the results from a complex permanent-income-hypothesis model with intergenerational equity objectives. Moreover, in some cases, this may not even be the main constraint facing a country. Thus, staff proposes that, to the extent relevant, teams use the results from their analysis on the need to save for future generations as an input in the constrained assessment of fiscal space.

\footnotetext{
${ }^{1}$ The MAC DSA sets the debt thresholds on a gross basis and, thus it is not possible to make an assessment on net debt. Nonetheless, staff could assess whether the outcome of the gross financing needs indicator varies depending on whether public financial assets are considered and use this as input for the final assessment (Stage 4).

${ }^{2}$ For LICs with market access for which the LIC DSF is still used, the default projection horizon is 20 years.
} 
Box 6. Assessing Space for Commodity Producers: Potential Additional Indicators

\section{Stage 1: Setting the Stage}

- Commodities share of GDP and of exports revenue

- Projected resource horizon

- Non-resource cyclically adjusted primary fiscal balance or, if assessment of cyclical position is challenging, non-resource primary fiscal balance (overall fiscal balance excl. resource revenues, resourcesector spending and interest payments)

- Volatility of fiscal revenue

- Non-oil GDP growth

- Debt service to non-oil revenue and to GDP

- Existence of public assets for short- and medium-term stabilization purposes 1/

- Capacity to access international markets on a durable and substantial basis $2 /$

\section{Stage 2: Financing and Debt Burden Indicators}

The state of public debt indicators

- Mandatory DSA customized stress test of a large decline in commodity prices

- For commodity producers with limited resource horizon, extension of the MAC DSA to at least five years beyond exhaustion

\section{Stage 4: Desk bottom-line}

- In the bottom-line assessment based on fiscal rules, when relevant, teams could incorporate intergenerational equity considerations

$1 /$ An alternative would be to report the ratio of public financial assets to commodity revenues. This can give a sense of the size of precautionary savings (for more details, see IMF, 2015).

2/ For a description, see IMF (2017b) Box 1.

\section{Contingent Liabilities}

\section{The past decade has underscored how shocks to public sector balance sheets can} impair fiscal sustainability and reduce fiscal space. Fiscal risks can arise from macroeconomic shocks or the realization of contingent liabilities - that is, obligations triggered by uncertain events (IMF, 2012b). These can be either explicit liabilities that are legally grounded (e.g., government loan guarantees) or implicit liabilities, where there is a public expectation of government responsibility not established in law (e.g., to bail out troubled subnational governments). Since 1990, countries have experienced a significant fiscal shock (around 6 percent of GDP) once every 12 years (IMF, 2016a). Nonetheless, the average increase in the debt-to-GDP ratio over the typical event was much larger (15 percent of GDP). This is because shocks are highly correlated, resulting in a distinct bunching of contingent liability realizations particularly during crisis periods (Figure 12). 


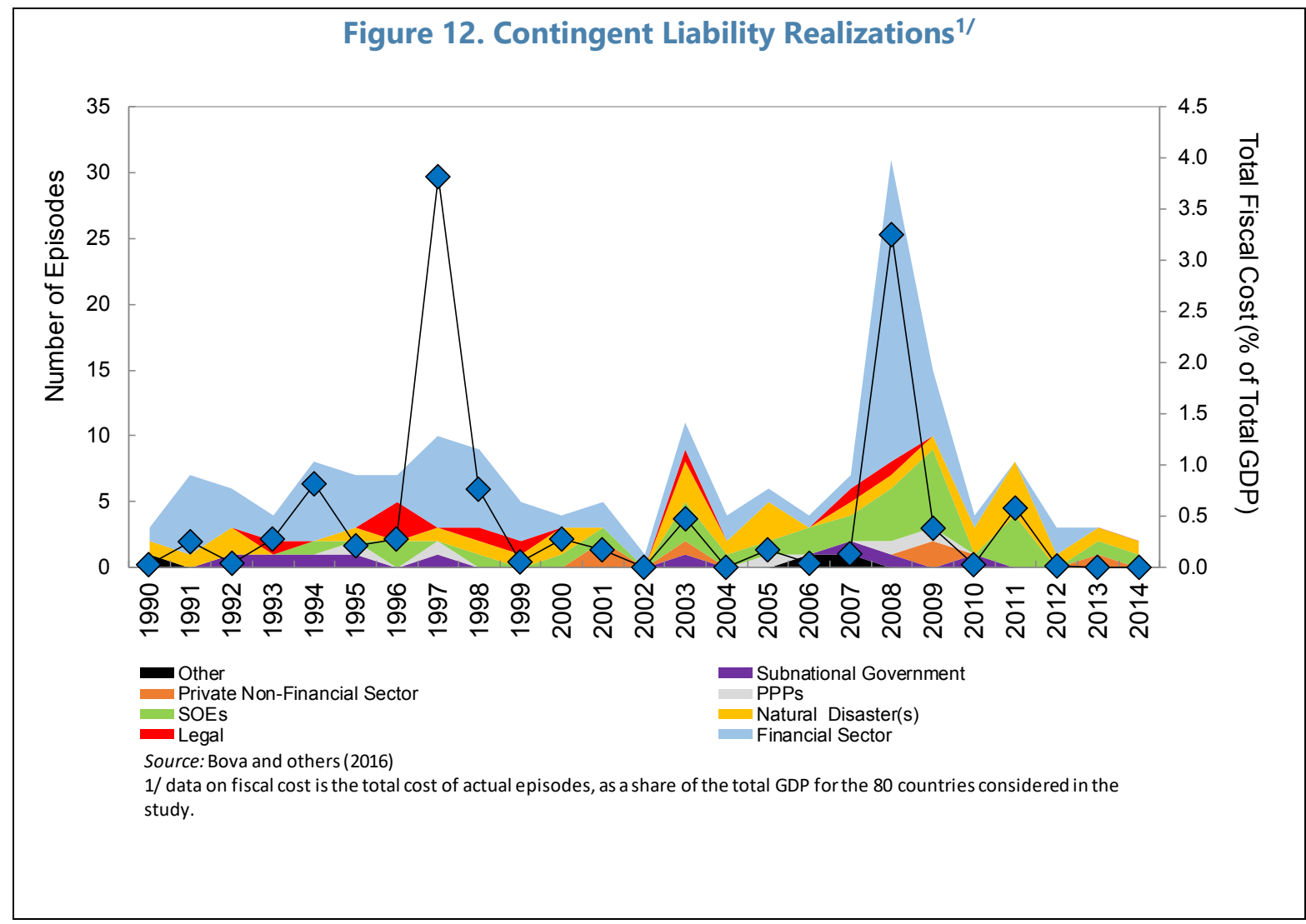

50. Fiscal risks will continue to put pressure on public debt in the future.

Notwithstanding the fact that significant contingent liabilities have already materialized, particularly those related to the financial sector, vulnerabilities remain high. In advanced economies, stocks of explicit contingent liabilities are large-averaging slightly above 50 percent of GDP in European countries (see Eurostat, 2018). ${ }^{1}$ In emerging market economies, there are significant risks related to state-controlled resource companies, infrastructure projects, the financial sector, and corporate debt. ${ }^{2}$ Contingent liabilities are also becoming a major source of fiscal risks in low-income countries where fiscal costs have reached up to 14 percent of GDP in the recent past-the most damaging episodes related to banking crises (Baum and others, 2017).

\section{The existing framework for assessing fiscal space partly takes into account some of}

these risks. The approach taken is to identify indicators of market access and debt dynamics that have historically been correlated with fiscal stress as well as to allow for country-specific shock scenarios. However, this approach could leave gaps in the coverage of important sources of fiscal

\footnotetext{
${ }^{1}$ The bulk of the contingent liabilities in European countries relate to the liabilities of government-controlled entities classified outside the general government.

2 For example, the IMF's Fiscal Transparency Evaluations conducted over the last four years identified contingent liabilities (implicit and explicit) of around 30 percent of GDP for Peru, 90 percent of GDP for the Philippines, 50 percent of GDP for Russia, and 57 percent of GDP for Turkey.
} 
risks which are not systematically considered, but are left at the discretion of country teams. ${ }^{1}$ These include risks associated with: (1) the financial sector; (2) legal claims; (3) state-owned enterprises (SOEs); (4) private non-financial corporates; (5) natural disasters; and (6) public-private partnerships (PPPs) (Figure 13). ${ }^{2}$ Although some of these risks may not have resulted in large fiscal costs in the recent past, they may in the future. This is particularly true for those risks where government exposures are not typically capped. As an example, only one third of countries limit explicit liabilities to SOEs, while only around 10 percent of countries limit contingent liabilities from PPPs (IMF, 2016a). Furthermore, as discussed above, indicators of market access are difficult to interpret and potentially unreliable as indicators of fiscal risks.

Figure 13. Costs and Frequency of Fiscal Risk Realizations

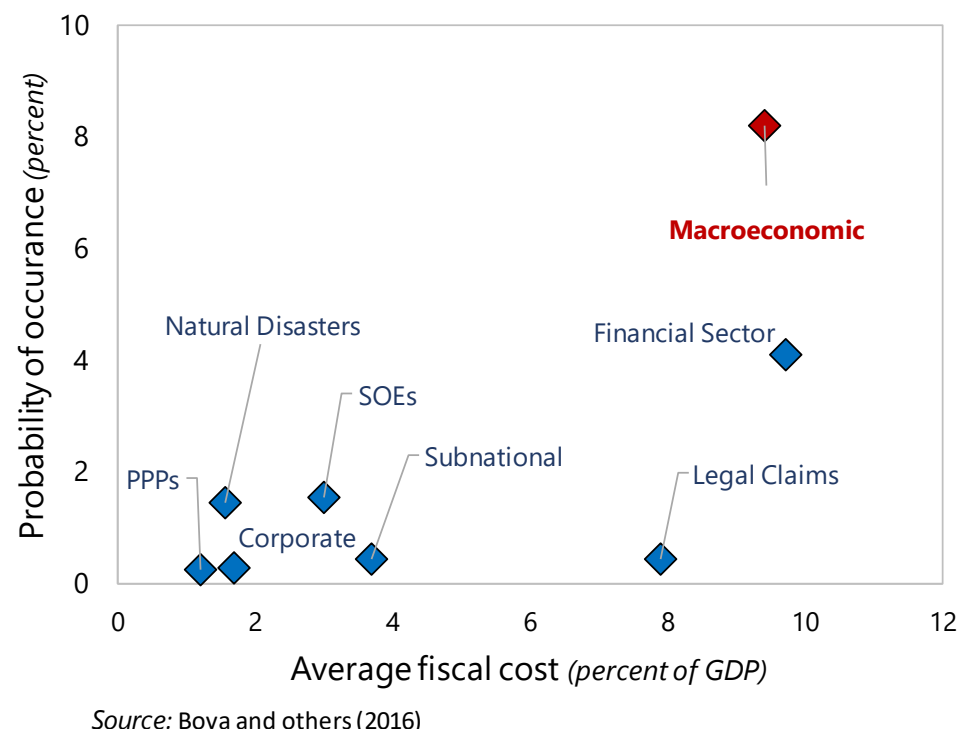

52. Going forward, several refinements could be introduced to better reflect the potential realization of contingent liabilities and its impact on fiscal space. Data limitations are an important constraint, especially for LICs, and even with good data some sources of risk will still be challenging to capture. Even with such caveats, where possible, compiling the best available information can help better understand the size and nature of the fiscal risks and inform the assessment of fiscal space. Therefore, the framework should include some additional indicators in setting the context in the first stage, and incorporate more explicitly the probability

\footnotetext{
${ }^{1}$ Among the pilot countries, only $1 / 3$ of the reports provided stress tests including the realization of contingent liabilities. All countries modeled financial sector contingent liabilities, except Pakistan and South Africa for which the contingent liabilities originated from SOEs.

2 Subnational governments are a significant, although less frequent, source of fiscal risks. Typically, the debt of subnational governments should be included in public debt aggregates. To the extent that subnational governments also face contingent liabilities (e.g., from local SOEs or PPPs), these should also be accounted for.
} 
of contingent liability realizations in the stress scenarios, given systemic importance and data availability (Box 7).

\section{Box 7. Incorporating Contingent Liabilities: Potential Additional Indicators}

\section{Stage 1: Setting the Stage}

Indicators on the size of contingent liabilities and fiscal costs stemming from the materialization of contingent liabilities in the recent past could be included for:

- the financial sector

- SOES

- PPPs

- legal claims

- cost of recent natural disasters (where relevant)

- size of corporate debt and episodes/costs of debt restructuring/crisis

- For countries with limited data, estimates of the stock-flow adjustment (SFAs) can also be included 1/

Annex III discusses the rationale behind the inclusion of these indicators, definitions, and potential data sources.

\section{Stage 2: Financing and Debt Burden Indicators}

- For those countries where the indicators in Stage 1 flag a potentially systemic risk if contingent liabilities were to materialize, Stage 2 should explicitly consider the probability of those fiscal shocks and related costs by including a stress test to capture the materialization of relevant contingent liabilities in the DSA 2/

1/ The SFA captures the discrepancy between the annual change in gross public debt and the budget deficit, stripping out the effect of the interest-growth differential (Weber, 2012). Changes in debt that are not explained by the deficit could indicate valuation effects but also the realization of contingent liabilities (Baum and others, 2017).

2/ To estimate the probability of such an event, country teams could follow the methodology in Bova and others (2016). The expected value of the contingent liability realization can then be calculated using the costs identified in Stage 1. Bova and others (2016) estimates a probit model whereby the contingent liability realization is a function of growth, the volatility of growth, inflation, the exchange rate, oil prices, and fiscal variables. Overall, growth appears to be one of the main determinants underscoring the high correlation between macro shocks and other fiscal risks. As a first step, teams could use these estimates to make forward-looking projections.

\section{FISCAL SPACE IN SURVEILLANCE: CONCLUSIONS AND A WAY FORWARD}

\section{This paper has documented that the fiscal space framework proved useful during} the pilot phase. The framework provided a structured approach for assessing fiscal space in a way that is comparable across countries-based on a uniform definition and taxonomy, as well as a common set of considerations and metrics. In doing so, it enhanced consistency and crosscountry comparability. The framework also delivered a clear sense of the extent of fiscal space in major economies, thus providing an important backdrop for policy discussions, helping 
implement multilateral messages in the WEO and ESR, and transparently signaling the Fund's views to member countries and the wider external audience. More generally, several insights about fiscal space in the current context emerged-notably that despite higher levels of public debt, there may be more space than initially thought as a result of low financing costs, favorable interest rate-growth differentials, longer debt maturities, and more local currency issuance. In addition, well-designed fiscal frameworks, and concrete long-term adjustment plans in the face of population aging can also help create more fiscal space. Finally, space can be sensitive to the initial state of the economy, e.g., where growth is cyclically or structurally weak, well-executed discretionary fiscal policies can preserve or even increase fiscal space by improving macroeconomic outcomes. That said, it is important to keep in mind that the framework is designed to assess the existence of fiscal space, and not its use.

54. The pilot fared favorably in most areas of implementation. Country teams applied the framework using a hierarchical approach to the different indicators and dimensions of fiscal space, with financing availability and baseline debt sustainability the primary filters. The final assessments were in line with the results of this approach. The framework worked well even in the context of fiscal rules, with teams able to arrive at assessments with and without taking them into account. Indeed, this approach highlighted the need to distinguish between the availability of fiscal space and constraints on its use that may be imposed by optimal fiscal policy or necessitated by existing fiscal rules or other socio-economic objectives. The resource implications of implementing the framework were relatively moderate.

\section{The framework should be strengthened in some aspects and amended to apply to a larger set of countries:}

- The indicators in the first stage could be expanded to include variables associated with vulnerability to funding market shocks.

- In the second stage, rather than a uniform approach to thresholds based on the level of development, there may be a case for using separate ones for different types of economies, notably for reserve currency issuers, who may be able to sustain higher levels of debt and gross financing needs. For some countries, a somewhat longer horizon for assessing the sustainability of debt and financing may also be appropriate. In addition, a broader set of fiscal risks could be considered under the stress tests, including contingent liabilities, where relevant.

- In the third stage, more customized scenarios featuring a different scale and composition of discretionary fiscal actions could be considered in addition to the standardized simulations, when warranted. This would help better reflect country specificities, provide additional power to discriminate between cases where the assessment is relatively less conclusive, and create a closer link to the policy advice. 
- Finally, while the broad logic of the framework still applies, it needs to be implemented somewhat differently for commodity producers and low-income countries who obtain a significant amount of external market or other non-concessional financing.

56. With such additional refinements, the framework appears primed to be integrated into regular Fund surveillance. Not all gaps can immediately be filled but, as described, the framework can be augmented in important ways to address many of the issues identified during the pilot phase. Going forward, staff would therefore propose that the framework be used to inform assessments of fiscal space across a wider segment of the membership. The initial deployment of the framework to the broader Fund membership will require changes to the existing infrastructure, requiring 9-12 months. Once the changes to the infrastructure are put in place, the estimated costs of applying the framework would be relatively moderate:

- Coverage. The pilots have already provided a benchmark view of the extent of fiscal space in 34 economies. For these economies, a new assessment would not immediately be needed. A gradual roll-out to others would commence in the Fall of 2018. For other economies using the MAC DSA, including commodity producers, a similar benchmark assessment would be expected as soon as feasible, ideally at the time of their next Article IV Staff Reports. This would include requests for new Fund programs. For LICs that have significant access to external market or other non-concessional financing, staff will augment the framework (see previous section) and initially test it on a few representative countries.

- Frequency. Fiscal space assessments would normally be conducted once every three years after the initial benchmark treatment, which would be considered valid in the interim. For ongoing programs, this would be done at the time of the Article IV. For many countries, fiscal space will evolve gradually so this will not be an entirely new exercise each time. A more frequent assessment may be necessitated in the face of large macroeconomic shocks, substantive shifts in funding availability or market sentiment, significant changes to fiscal policy (either baseline or under staff recommendations) and fiscal rules, or updates to the fiscal space framework.

- Treatment. The fiscal space assessment would normally be featured as a succinct write-up in the Staff Report together with supporting indicators. The write-up would include a concise discussion of how the bottom-line was reached by using the different stages of the framework, both with and without any extant fiscal rules. Of course, some countries may require a more extensive treatment in particular years. In the case of large and persistent divergences between the assessment with and without fiscal rules, teams could consider an evaluation of the rule.

- Scenario analysis. Since the scenario analysis in the third stage has been the most resourceintensive part of the framework, it would not be required for countries where financing availability is prohibitive, such that a fiscal expansion cannot be funded and space is, therefore, by definition limited. 
57. Analytical agenda. Going forward, there is a need to develop some greater guidance on the use of appropriate thresholds and time horizons for debt burden indicators, the optimal use of fiscal space, and the interface between fiscal space assessments and external sector assessments. Work is planned in these areas in the context of the upcoming MAC DSA review, the development of a framework to inform assessment of the fiscal stance by FAD, and the reexamination of optimal medium-term fiscal policies in the context of the ESR. In addition, as new methods for assessing fiscal risk and sustainability are developed and more experience is gained through implementation, the fiscal space assessment framework could be updated accordingly.

\section{ISSUES FOR DISCUSSION}

- Do Directors agree that the fiscal space pilot largely met its key objectives?

- Do Directors concur that the fiscal space framework has enhanced the sharpness and consistency of fiscal space assessments in Staff Reports?

- Do Directors support the framework being used more systematically as a tool for Fund surveillance?

- Do Directors agree with the thrust of the enhancements suggested to better capture fiscal risks from contingent liabilities, and specific characteristics of low-income countries and commodity producers?

- Do Directors support staff's proposed agenda for analytical work to help further strengthen the framework and its application in bilateral and multilateral surveillance? 


\section{Annex I. Fiscal Space Framework: Simulations}

Teams used DSGE models or the MAC DSA template to simulate two alternative fiscal expansion scenarios in the third stage of the fiscal space framework. These were stylized and standardized to ensure cross-country comparability, and based on relatively large shocks in order to increase their signaling value.

Design. Both scenarios assumed a stimulus of 2 percent of GDP a year over the baseline in years $t$ and $t+1$. Starting in year $t+2$, the fiscal balance adjusts based on a built-in fiscal reaction function. Automatic stabilizers reduce the actual change in fiscal balance below the stimulus. Country-by-country effectiveness of spending was informed by FAD input. The two scenarios were based on the following specific assumptions:

\section{Upside Scenario}

- High multiplier package. 25 percent of stimulus for infrastructure spending with high short-run multiplier and notable long-term multiplier through indirect effects on private investment and potential output; the remaining 75 percent is split between transfers and government consumption (also with high short-run multiplier).

- Monetary accommodation. The central bank keeps interest rates at baseline level.

- No change to risk premium.

\section{Downside Scenario}

- Low multiplier package. 25 percent of stimulus is on reduction in corporate income tax; the remaining 75 percent is split between reductions in labor income tax and consumption tax (VAT).

- No monetary accommodation. Monetary policy reaction function allowed to operate and interest rates adjust endogenously to higher growth and inflation.

- Higher risk premium. The sovereign risk premium rises to the 75th percentile based on the country's long-run experience and also impacts the private sector interest rate and, thus, private investment and growth. 


\section{Annex II. Fiscal Space Assessments in the Pilots ${ }^{1}$}

\section{A. Coverage of Public Debt}

Coverage

Central government

General government

Federal government

Non-financial public sector

Consolidated public sector

Consolidated public sector, including public guarantees

General government, including federal guarantees

General government (as per authorities' definition)

Central government, excluding deposits at the Treasury from third parties (SOEs, private entities and individuals)

Central government, state-owned enterprises, public sector development banks, and social security funds. Excludes local governments

\section{Country}

Algeria, Argentina, Korea, Saudi Arabia

Australia, Canada, Egypt, France, Germany, Indonesia, Iran, Israel, Italy, Japan, Kazakhstan, Netherlands, Nigeria, Pakistan, Philippines, Poland, South Africa, Spain, Sweden, United States

Malaysia

Brazil, Colombia, Turkey

United Kingdom

Thailand

Russia

China

Morocco

Mexico

${ }^{1}$ The discussion in this Annex, underlying tables and figures, and policy advice are based on analysis conducted in the lead-up to the 2016 (for Australia, Iran and the Netherlands) or 2017 (for the other pilots) Article IV Consultation, unless otherwise indicated. In a few cases there has been a subsequent Article IV consultation, but no material change in the fiscal space assessment. 


\section{B. Discussion of Assessments}

To discuss the assessments, it is useful to look at indicators of countries' fiscal position using the logic of the sifter as discussed in the main text. In particular, we employ the following sequence:

- First, we examine indicators of (i) stable market financing availability and (ii) debt composition to get a sense of the financing situation of the fiscal position.

- Second, we consider indicators of (iii) the trajectory of debt burden indicators; (iv) the realism of medium-term adjustment needs; and (v) long-term fiscal pressures to assess the sustainability of the fiscal position.

- Third, we evaluate the extent to which the signal emanating above is confirmed by the simulations.

As noted in the main text and illustrated below, these various aspects of fiscal space are obviously interdependent, e.g., access to finance will depend on the trajectory of debt and vice versa, but using this classification helps in structuring the discussion. It is, in addition, important to note that even if countries are grouped together in some respect in the discussion below, there are often substantial differences, and the intent is not to provide a complete and granular picture of individual countries, but to illustrate the results from the fiscal space framework depicted in Figure 1 of the main text.

\section{Financing Considerations}

Access to affordable and stable financing is a pre-requisite for a country to have any fiscal space, which four of the countries were deemed to be lacking. Argentina only regained market access recently, but this is still seen as uncertain given past lack of credibility in the markets and a high share of debt denominated in foreign currency that increases vulnerability to shocks. For Nigeria, even though the debt level is relatively low, the interest payment-to-revenue ratio is high and unsustainable over the medium term, and it has faced high financing costs. For South Africa, borrowing spreads have also been elevated due to concerns about, among other things, declining commodity prices, droughts, and domestic structural problems, reflected in lower actual and potential output, rising debt to GDP, and a negative view of the main rating agencies. Likewise in Egypt, large fiscal deficits and rising general government debt are reflected in wide spreads even though the share of foreign currency debt is low. In these cases, fiscal space is limited as without secure access to finance, a loosening of the fiscal stance cannot be funded. There are also several other emerging markets where spreads at times have been moderately high in the last few years or more recently, such as Algeria, Brazil, Kazakhstan and Pakistan. In these cases, access to stable and affordable financing is still an important aspect to be considered when assessing the existence of fiscal space, even if it is not by itself determinative. In the case of Kazakhstan, access is cushioned by the availability of large and liquid financial assets. For Iran, spreads are not available, again suggesting need for caution on the assessment of current financing availability. 
Debt profiles also matter for the possibility of financing fiscal policy in the future, and were an important factor for many emerging markets in judging fiscal space. Specifically, in one quite diverse group of countries the fiscal position and overall debt levels were reasonably strong, but some aspects of the debt composition made them, to different degrees, vulnerable to changes in foreign investor sentiments and capital outflows, contributing to overall assessments of some fiscal space (before taking fiscal rules into account). Colombia, Indonesia, Mexico, and Poland, and to a lesser extent, the Philippines and Turkey have elevated shares of public debt held by non-residents and of debt in foreign currency. For example, Indonesia is notable with less than 30 percent of debt-to-GDP but over 65 percent of it held by non-residents and almost 43 percent in foreign currency. Turkey, Poland, and Algeria to different degrees, also have high external financing needs at 28,22, and 18 percent of GDP, respectively, to consider. Malaysia has a moderately high share of public debt held by non-residents, though not in foreign currency, which paired with high external financing needs at 47 percent of GDP, and moderately high spreads, limits the ability to implement a looser stance than in the baseline without potentially endangering market access. Morocco has moderately high shares of non-resident and foreign currency public debt, and has also had some bouts of moderately high spreads in the past, which combined, constrain fiscal space.

\section{Sustainability Considerations}

In many countries, especially advanced economies, but also some emerging markets, sustainability considerations, as reflected in high levels of debt and gross financing needs, dominated the assessment of fiscal space. Among EMs, both Brazil and Pakistan face moderately high risks to financing, but elevated GFN and debt levels make fiscal space limited as fiscal loosening relative to baseline could endanger debt sustainability and market access. Many advanced economies have high debt levels and/or high GFNs, and in the case of Italy and Spain, despite reasonable access to financing, concerns about debt sustainability are severe enough to imply that there is limited fiscal space. France has lower GFNs, but high debt at over 95 percent of GDP still constrains fiscal space. Japan and the United States also both have high GFNs needs and debt stocks, but due to very strong market financing access, at least partly on account of having reserve currencies, there is still some fiscal space, which is similar to the United Kingdom, although GFNs there are lower. Canada has some fiscal space despite high debt and moderately high GFNs, reflecting substantial assets and access to cheap financing on account of high credibility, as seen in sovereign credit ratings. In the case of China and Israel, relatively low debt and GFN levels are somewhat tempered by an increasing debt trajectory under the baseline (also the case in Saudi Arabia) and a moderately high risk of breaching the debt benchmark under a probabilistic approach.

In a few cases, debt and financing needs seem manageable, but large medium-term adjustment needs put pressure on the availability of fiscal space. In particular countries hit by permanently lower oil prices such as Saudi Arabia, Algeria, and Kazakhstan, face challenging adjustment needs to keep the fiscal position sustainable. Yet, the favorable starting points in terms of debt and GFNs still allows for some fiscal space that can be used for more gradual adjustments. The availability of sizeable accumulated financial assets can also serve as a further cushion, which in the case of Kazakhstan provide substantial fiscal space. 


\section{Even if near and medium-term indicators are generally favorable, long-term fiscal} pressures, such as due to aging, can still weigh on fiscal space. Most countries, if not all, face some long-term fiscal challenges, but these are often not immediately critical for assessing fiscal space for discretionary fiscal measures without endangering market access and debt sustainability. However, in Thailand, long-term challenges are substantial and reduce available fiscal space, even though there is some. Also in the case of China, long-term adjustment needs are significant, and even more challenging when the level of debt is augmented by debt of Local Government Financing Vehicles and entities such as government-guided funds. Nevertheless, China still has some fiscal space due to relatively favorable indicators in other dimensions. In Korea, aging related long-term pressures are a major fiscal challenge that will require adjustment down the road, but the strength of the fiscal position in other dimensions still leaves substantial room for discretionary fiscal policy in the interim. The same holds true in Germany and the Netherlands, where long-term pressures are lower but still material. Conversely, in Sweden and Australia, relatively favorable long-term fiscal positions, in part due to entitlement reforms, reinforce the assessment of substantial fiscal space.

The results from simulations of a fiscal loosening compared to baseline provided reassurance that the conclusions from the previous stages held up also in a dynamic analysis. Overall, the debt and gross financing dynamics did not change to the extent that the conclusions from the previous analysis were materially altered. Nevertheless, they did help to confirm the bottom-line assessments, including in some relatively marginal cases. 


\section{Treatment of Fiscal Space in Pilot Staff Reports}

\begin{tabular}{|c|c|c|}
\hline Country & Bottom-line Assessment & Policy Advice \\
\hline \multicolumn{3}{|c|}{ Advanced Economies } \\
\hline Australia & $\begin{array}{l}\text { Australia has substantial fiscal space. Standard metrics suggest } \\
\text { that Australia has fiscal space under both the baseline and } \\
\text { economic stress scenarios. For example, sovereign spreads over U.S. } \\
\text { bonds have been relatively moderate in the past } 12 \text { months (at most } \\
64 \text { basis points); gross debt is still low at } 40 \text { percent of GDP } \\
\text { compared with other major advanced economies. }\end{array}$ & $\begin{array}{l}\text { Gradual consolidation and support } \\
\text { structural reform. Use fiscal space for } \\
\text { a gradual fiscal consolidation while } \\
\text { raising infrastructure spending and } \\
\text { supporting structural reforms. }\end{array}$ \\
\hline Canada & $\begin{array}{l}\text { Canada has some fiscal space. Although general government } \\
\text { gross debt is relatively high at over } 92 \text { percent of GDP, with sizable } \\
\text { financial assets, general government net debt is only } 28 \text { percent of } \\
\text { GDP, far below the advanced economy average of } 72 \text { percent of } \\
\text { GDP. Market confidence in Canada's fiscal prudence is high, with its } \\
\text { sovereign long-term bonds (AAA rating) trading at a premium } \\
\text { relative to U.S. 10-year treasury bonds. }\end{array}$ & $\begin{array}{l}\text { Expansionary stance to support } \\
\text { cyclical recovery. Fiscal policy should } \\
\text { be geared toward ensuring that the } \\
\text { cyclical recovery is secure and } \\
\text { inclusive. The fiscal stance should } \\
\text { remain expansionary this year. As the } \\
\text { output gap closes, no further increase } \\
\text { in the deficit resulting from } \\
\text { discretionary spending or tax cuts will } \\
\text { be required. }\end{array}$ \\
\hline France & $\begin{array}{l}\text { France has limited fiscal space under European rules, and recent } \\
\text { consolidation efforts have not delivered the envisaged results. } \\
\text { Despite the ongoing recovery, the ratio of public debt to GDP has } \\
\text { continued to rise. France is still subject to the Excessive Deficit } \\
\text { Procedure. Debt dynamics could become problematic in the event } \\
\text { of a growth shock, with debt climbing to well above } 100 \text { percent of } \\
\text { GDP. While France still has some fiscal space to respond to shocks } \\
\text { there is little near-term room for maneuver while the deficit remains } \\
\text { above } 3 \text { percent of GDP. }\end{array}$ & $\begin{array}{l}\text { Gradual expenditure-based fiscal } \\
\text { consolidation planned by the } \\
\text { government is generally } \\
\text { appropriate. Reducing the budget } \\
\text { deficit to } 1 / 2 \text { percent of GDP by } 2022 \\
\text { would help place public debt on a } \\
\text { downward trajectory and create room } \\
\text { for fiscal policy maneuver without } \\
\text { unduly detracting from the recovery. It } \\
\text { is also broadly consistent with } \\
\text { European and national constitutional } \\
\text { rules. }\end{array}$ \\
\hline Germany & $\begin{array}{l}\text { Fiscal consolidation has created substantial fiscal space. Fiscal } \\
\text { policy in Germany has prioritized consolidation, including by saving } \\
\text { budgetary overperformance, successfully strengthening Germany's } \\
\text { fiscal position and creating the budgetary room to address } \\
\text { unexpected developments. The public debt ratio fell back to pre- } \\
\text { crisis levels in 2016, and is set to cross below the } 60 \text { percent of GDP } \\
\text { Stability and Growth Pact benchmark in 2020. The German } \\
\text { government is expected to retain ample access to financing through } \\
\text { the foreseeable future, even in the event of a large fiscal stimulus. }\end{array}$ & $\begin{array}{l}\text { Use fiscal space for growth } \\
\text { initiatives. Going forward, a looser } \\
\text { fiscal position would allow for further } \\
\text { investment in Germany's growth } \\
\text { potential, while also supporting } \\
\text { external adjustment. The available } \\
\text { fiscal space should be used for } \\
\text { initiatives that enhance the growth } \\
\text { potential of the economy, such as } \\
\text { investment in physical and digital } \\
\text { infrastructure, childcare, refugee } \\
\text { integration, and relief of the tax } \\
\text { burden on labor. }\end{array}$ \\
\hline Israel & $\begin{array}{l}\text { Israel has some fiscal space if it were to be needed, with } \\
\text { government debt projected to remain below the } 85 \text { percent } \\
\text { threshold for advanced economies and gross financing needs at } \\
\text { manageable levels of around } 10 \text { percent of GDP. However, Israel } \\
\text { faces wider uncertainties than most advanced economies, making } \\
\text { the government's medium-term debt target of } 60 \text { percent of GDP a } \\
\text { more robust benchmark for assuring that large scale fiscal support } \\
\text { can be deployed if the need arises. }\end{array}$ & $\begin{array}{l}\text { Gradual consolidation to protect } \\
\text { fiscal buffers. Israel faces wider } \\
\text { uncertainties than most advanced } \\
\text { economies, making the government's } \\
\text { medium-term debt target of } 60 \\
\text { percent of GDP a robust benchmark } \\
\text { for assuring that large scale fiscal } \\
\text { support can be deployed if the need } \\
\text { arises. }\end{array}$ \\
\hline
\end{tabular}




\begin{tabular}{|c|c|c|}
\hline Country & Bottom-line Assessment & Policy Advice \\
\hline Italy & $\begin{array}{l}\text { High debt leaves Italy vulnerable to adverse macroeconomic and } \\
\text { confidence shocks, with limited space for stabilization purposes or } \\
\text { for growth-enhancing measures, such as increased spending on } \\
\text { education or infrastructure or lower tax rates on factors of } \\
\text { production. Absent consolidation, debt will broadly stabilize at } \\
\text { current ratios and rise as monetary conditions normalize. Under } \\
\text { moderate shock scenarios, debt is projected to increase further, } \\
\text { challenging fiscal sustainability. }\end{array}$ & $\begin{array}{l}\text { Start credible adjustment to firmly } \\
\text { reduce debt. Considering the limited } \\
\text { fiscal space, it is advisable to start a } \\
\text { credible adjustment while financing } \\
\text { conditions remain favorable and } \\
\text { ensure public debt begins to decline } \\
\text { firmly. If adverse shocks materialize, } \\
\text { automatic stabilizers should be } \\
\text { allowed to operate. }\end{array}$ \\
\hline Japan & $\begin{array}{l}\text { Japan's public debt is at an unprecedented high level. However, } \\
\text { limited funding risks and low borrowing costs, underpinned by JGB } \\
\text { purchases by the BoJ and domestic investors' home bias, allow } \\
\text { some fiscal space in the near term, provided the medium-term } \\
\text { debt trajectory is anchored by a credible fiscal consolidation plan. }\end{array}$ & $\begin{array}{l}\text { At least neutral near-term stance to } \\
\text { not withdraw stimulus. There is } \\
\text { some fiscal space in the near term, } \\
\text { provided the medium-term debt } \\
\text { trajectory is anchored by a credible } \\
\text { fiscal consolidation plan. The fiscal } \\
\text { stance should be at least broadly } \\
\text { neutral in 2018-avoiding the } \\
\text { scheduled withdrawal of fiscal } \\
\text { stimulus-followed by gradual } \\
\text { consolidation in subsequent years. }\end{array}$ \\
\hline Korea & $\begin{array}{l}\text { Korea has substantial fiscal space to implement a more active } \\
\text { fiscal policy. With central government debt below } 40 \text { percent of } \\
\text { GDP and an average consolidated central government surplus of } 1.2 \\
\text { percent of GDP since 2010, Korea has one of the soundest fiscal } \\
\text { positions among advanced economies. The debt-to-GDP ratio is } \\
\text { expected to remain below } 40 \text { percent until at least 2032, with an } \\
\text { average deficit of } 0.7 \text { percent of GDP, taking into account the } \\
\text { increase in pension- and health-related public spending, and } \\
\text { assuming no change in the revenue-to-GDP ratio. }\end{array}$ & $\begin{array}{l}\text { Fiscal policy needs to become } \\
\text { significantly more expansionary to } \\
\text { support inclusive growth and reduce } \\
\text { excessive external imbalances. Staff } \\
\text { recommends that the government } \\
\text { reduces the structural balance toward } \\
\text { zero by at least } 0.5 \text { percentage point } \\
\text { each year during the } \\
\text { coming years. This should be achieved } \\
\text { largely through higher expenditures } \\
\text { on social policies and structural } \\
\text { reforms. }\end{array}$ \\
\hline Netherlands & $\begin{array}{l}\text { The Netherlands has substantial fiscal space. The country faces } \\
\text { very limited financing risks, and the level and trajectory of debt and } \\
\text { gross financing needs as well as medium-term fiscal adjustment } \\
\text { needs do not raise sizable risks. Over the longer term, the } \\
\text { Netherlands faces some additional adjustment needs related to } \\
\text { demographics. Only in a very severe stress scenario involving a large } \\
\text { banking sector shock that would be in the tail of the distribution } \\
\text { would debt burden indicators turn unfavorable. Use of fiscal room } \\
\text { should, however, be compliant with the SGP. }\end{array}$ & $\begin{array}{l}\text { Use fiscal space for growth } \\
\text { enhancing measures. Use fiscal } \\
\text { space, consistent with meeting the } \\
\text { Stability and Growth Pact } \\
\text { requirements, to support the recovery } \\
\text { in the short term, particularly through } \\
\text { additional growth-enhancing } \\
\text { spending in public R\&D and education } \\
\text { or through further reducing the tax } \\
\text { wedge for workers at the margin of } \\
\text { the labor force. }\end{array}$ \\
\hline Spain & $\begin{array}{l}\text { Spain's fiscal space is limited. Spain's public debt, at almost } 100 \\
\text { percent of GDP, is nearly three times higher than on the eve of the } \\
\text { global financial crisis and its annual gross financing need, relative to } \\
\text { GDP, is the highest in the European Union. In addition, Spain's } \\
\text { population dynamics imply significant pressure on age-related } \\
\text { spending over the medium to long term. Moreover, fiscal support to } \\
\text { the financial system, as a legacy of the banking crisis, is not yet } \\
\text { complete with another } 0.1 \text { percent of GDP budgeted in } 2017 \text {. }\end{array}$ & $\begin{array}{l}\text { Further fiscal consolidation to } \\
\text { rebuild buffers. Staff recommends } \\
\text { maintaining the current pace of fiscal } \\
\text { adjustment by identifying measures } \\
\text { that would reduce the structural } \\
\text { primary deficit annually by about } 0.5 \\
\text { percent of GDP until structural balance } \\
\text { is achieved. }\end{array}$ \\
\hline
\end{tabular}




\begin{tabular}{|c|c|c|}
\hline Country & Bottom-line Assessment & Policy Advice \\
\hline Sweden & $\begin{array}{l}\text { It is evident that Sweden's healthy fiscal position offers } \\
\text { substantial fiscal space were it to be needed, which is not } \\
\text { currently the case. }\end{array}$ & $\begin{array}{l}\text { The decline in the surplus to the new } \\
\text { medium-term target should be } \\
\text { relatively gradual, such as by } \\
\text { phasing it over } 2-3 \text { years. Under the } \\
\text { assumption that the surplus target is } \\
\text { reached by } 2021 \text {, public debt is } \\
\text { expected to decline to } 33 \text { percent of } \\
\text { GDP that year, below the } 35 \text { percent } \\
\text { benchmark added to Sweden's fiscal } \\
\text { framework. }\end{array}$ \\
\hline $\begin{array}{l}\text { United } \\
\text { Kingdom }\end{array}$ & $\begin{array}{l}\text { There is some fiscal space to help smooth the adjustment under a } \\
\text { tail risk scenario. The UK faces limited financing risks in the near } \\
\text { term despite a relatively high debt burden. Sovereign bond spreads } \\
\text { have remained exceptionally low following last year's referendum. }\end{array}$ & $\begin{array}{l}\text { Steady fiscal consolidation, with an } \\
\text { emphasis on pro-growth spending } \\
\text { and tax reforms, remains critical to set } \\
\text { the public debt ratio on a downward } \\
\text { path and rebuild buffers against future } \\
\text { shocks. }\end{array}$ \\
\hline $\begin{array}{l}\text { United } \\
\text { States }\end{array}$ & $\begin{array}{l}\text { The U.S. has some fiscal space. The U.S faces low financing costs } \\
\text { and benefits from strong demand for high quality liquid assets and } \\
\text { the U.S. dollar's status as a reserve currency. Over a longer horizon, } \\
\text { if the fiscal costs associated with an aging demographic remain } \\
\text { unaddressed, the debt-GDP ratio will continue to rise which may call } \\
\text { into question the creditworthiness of the federal government. }\end{array}$ & $\begin{array}{l}\text { No use of fiscal space. The U.S. has } \\
\text { some fiscal space but an expansionary } \\
\text { fiscal policy would be } \\
\text { counterproductive at this stage of the } \\
\text { cycle. Instead, a gradual fiscal } \\
\text { consolidation should be pursued. }\end{array}$ \\
\hline \multicolumn{3}{|c|}{ Emerging Markets } \\
\hline Algeria & $\begin{array}{l}\text { Algeria has some fiscal space. Fiscal savings have been nearly } \\
\text { depleted, but public debt remains low, and external debt is nearly } \\
\text { nonexistent. Public sector gross financing needs decline sharply } \\
\text { under the MTBF and remain manageable even under more } \\
\text { expansionary scenarios simulated by staff. Debt levels decline under } \\
\text { the MTBF and remain well below benchmark levels for emerging } \\
\text { markets in expansionary scenarios. }\end{array}$ & $\begin{array}{l}\text { More gradual spending cuts to } \\
\text { support growth. Some fiscal space } \\
\text { exists to cut spending more gradually } \\
\text { than planned if the adjustment were } \\
\text { coupled with exchange rate } \\
\text { depreciation and increased borrowing. } \\
\text { A more gradual fiscal consolidation } \\
\text { would have less impact on growth } \\
\text { while still restoring fiscal sustainability. }\end{array}$ \\
\hline Argentina & $\begin{array}{l}\text { The high deficit and sizeable gross financing needs mean } \\
\text { Argentina's fiscal space is limited. Higher interest payments have } \\
\text { led the overall general government deficit to increase from } 6 \\
\text { percent of GDP in } 2015 \text { to } 7 \text { percent of GDP in } 2017 \text {. }\end{array}$ & $\begin{array}{l}\text { A frontloaded reduction in general } \\
\text { government spending - that targets } \\
\text { an elimination of the primary deficit } \\
\text { by } 2019-\text { would allow a more } \\
\text { balanced policy mix and create space } \\
\text { for a reduction of the tax burden. }\end{array}$ \\
\hline Brazil & $\begin{array}{l}\text { Brazil has limited space for a growth-supportive fiscal expansion, } \\
\text { as evidenced by the DSA. The level and trajectory of debt and gross } \\
\text { financing needs raise significant risks. In the baseline scenario, } \\
\text { involving implementation of reforms already underway, debt keeps } \\
\text { rising to over } 90 \text { percent of GDP in 2022/2023, and only starts } \\
\text { declining in } 2024 .\end{array}$ & $\begin{array}{l}\text { Speed up consolidation when } \\
\text { growth strengthens. Under current } \\
\text { plans and policies, primary balances } \\
\text { will improve relatively slowly and the } \\
\text { public debt-to-GDP ratio would only } \\
\text { begin to decline many years from } \\
\text { now, posing significant risks, especially } \\
\text { if the economic environment turns less } \\
\text { favorable. }\end{array}$ \\
\hline China & $\begin{array}{l}\text { China has some fiscal space, but the extent depends on whether } \\
\text { liabilities from off budget investments are considered. China's } \\
\text { general government net borrowing and debt were } 33 / 4 \text { and } 37 \\
\text { percent of GDP, respectively, in } 2016 \text {. Given that the primary } \\
\text { balance is projected to be broadly stable and China has a favorable } \\
\text { growth-interest rate differential, official government debt is } \\
\text { projected to rise gradually and stabilize over the long run. However, } \\
\text { "augmented" debt is estimated at } 62 \text { percent of GDP in } 2016 \text { and } \\
\text { projected to rise to } 92 \text { percent in } 2022 \text {. }\end{array}$ & $\begin{array}{l}\text { Use fiscal space to support } \\
\text { structural reform. Some fiscal space } \\
\text { to be used if done in support of } \\
\text { structural reforms, or for aggregate } \\
\text { demand management only in an } \\
\text { extreme downside scenario. Fiscal } \\
\text { space should not be used to delay } \\
\text { consolidation in itself. }\end{array}$ \\
\hline
\end{tabular}




\begin{tabular}{|c|c|c|}
\hline Country & Bottom-line Assessment & Policy Advice \\
\hline Colombia & $\begin{array}{l}\text { With public debt levels and gross financing needs below stress- } \\
\text { benchmarks, Colombia has some fiscal space for additional peace } \\
\text { expenditure while protecting the credibility of the fiscal rule. }\end{array}$ & $\begin{array}{l}\text { Fiscal sustainability should remain } \\
\text { a key criterion } \\
\text { in the implementation of the peace } \\
\text { agreement. Ensuring debt } \\
\text { sustainability remains a priority amid } \\
\text { sizeable gross external financing } \\
\text { needs and higher foreign holdings of } \\
\text { debt. }\end{array}$ \\
\hline Egypt & $\begin{array}{l}\text { Egypt has limited fiscal space, reflecting the sizeable stock of debt } \\
\text { and high gross financing needs. }\end{array}$ & $\begin{array}{l}\text { Egypt needs to create fiscal space } \\
\text { for its significant spending needs on } \\
\text { infrastructure, health, education, and } \\
\text { social protection. This can be achieved } \\
\text { without compromising debt } \\
\text { sustainability through continued tax } \\
\text { policy and tax administration reforms. }\end{array}$ \\
\hline Indonesia & $\begin{array}{l}\text { Indonesia has some fiscal space. Despite small gross financing } \\
\text { needs and low debt, fiscal space is constrained by weak revenues, a } \\
\text { fiscal deficit near the statutory ceiling, and the large reliance on } \\
\text { external financing. Shallow domestic financial markets and an open } \\
\text { capital account render the economy vulnerable to capital flow } \\
\text { volatility. Adhering to the statutory } 3 \text { percent of GDP deficit ceiling } \\
\text { is critical to maintain fiscal discipline and protect investor } \\
\text { confidence. }\end{array}$ & $\begin{array}{l}\text { Given the slightly negative output } \\
\text { gap, a more gradual fiscal } \\
\text { adjustment would be more } \\
\text { appropriate to protect growth while } \\
\text { gradually lowering the primary deficit } \\
\text { and } \\
\text { rebuilding fiscal buffers. Early } \\
\text { implementation of a medium-term } \\
\text { revenue strategy to finance growth- } \\
\text { enhancing priority spending and } \\
\text { structural reforms is critical. }\end{array}$ \\
\hline Iran & $\begin{array}{l}\text { With ample, long-lasting oil resources, Iran has some fiscal space. } \\
\text { The fall in oil prices since their } 2014 \text { peak further reduced fiscal } \\
\text { space and buffers already eroded under sanctions. Although public } \\
\text { debt is set to rise above } 40 \text { percent of GDP as new debt is issued to } \\
\text { clear government liabilities, it remains sustainable and robust to } \\
\text { shocks. }\end{array}$ & $\begin{array}{l}\text { Gradual consolidation to support } \\
\text { growth. Iran has some space to target } \\
\text { a gradual adjustment in the non-oil } \\
\text { fiscal deficit to the Permanent Income } \\
\text { Hypothesis norm of } 5.6 \text { percent of } \\
\text { non-oil GDP over the long-term. This } \\
\text { balances the need to support growth } \\
\text { and keeps debt manageable and in- } \\
\text { line with the capacity of the nascent } \\
\text { domestic debt market. }\end{array}$ \\
\hline Kazakhstan & $\begin{array}{l}\text { While Kazakhstan has substantial fiscal space, strong buffers } \\
\text { should be maintained and medium-term consolidation is needed. } \\
\text { Financing and fiscal adjustment risks are mitigated by Kazakhstan's } \\
\text { relatively large sovereign wealth fund; NFRK assets amount to } 45 \\
\text { percent of GDP, and public debt is expected to remain below } 25 \\
\text { percent of GDP. However, renewed oil price shocks, slower growth, } \\
\text { persistently higher fiscal deficits, or a materialization of contingent } \\
\text { liabilities could erode buffers. }\end{array}$ & $\begin{array}{l}\text { Gradual consolidation to support } \\
\text { growth. Fiscal policy has appropriately } \\
\text { been supportive of activity, but with } \\
\text { recovery, the focus should shift to } \\
\text { ensuring long-term sustainability. To } \\
\text { ensure fiscal sustainability and strong } \\
\text { buffers, the non-oil deficit should be } \\
\text { reduced gradually over the medium } \\
\text { term, so that headwinds on growth are } \\
\text { minimized. }\end{array}$ \\
\hline Malaysia & $\begin{array}{l}\text { Malaysia is judged to have limited fiscal space in the near term } \\
\text { but would have increased space in the medium term as the level } \\
\text { of government debt falls over the next five years under the baseline. } \\
\text { The general financing environment, baseline debt, and gross } \\
\text { financing dynamics are relatively favorable, while medium-term } \\
\text { adjustment needs are manageable. However, Malaysia continues to } \\
\text { face large external financing requirements, elevated nonresident } \\
\text { holdings of MGS, and a relatively high level of contingent liabilities. }\end{array}$ & $\begin{array}{l}\text { Support planned consolidation. The } \\
\text { planned consolidation will help } \\
\text { alleviate risks from elevated } \\
\text { government debt levels and } \\
\text { contingent liabilities, and build fiscal } \\
\text { space for future expansionary policy, } \\
\text { as needed. }\end{array}$ \\
\hline
\end{tabular}




\begin{tabular}{|c|c|c|}
\hline Country & Bottom-line Assessment & Policy Advice \\
\hline Mexico & $\begin{array}{l}\text { Mexico has some fiscal space. Fiscal space remains constrained by } \\
\text { large tax compliance gaps and spending inefficiencies, as well as the } \\
\text { need to reduce public debt in relation to GDP. There was agreement } \\
\text { that fiscal policy should continue to aim at keeping the public debt- } \\
\text { to-GDP ratio on a downward trajectory. The trajectory of Mexico's } \\
\text { public debt and gross financing needs is overall robust to standard } \\
\text { shocks, while medium- and long term adjustment needs are } \\
\text { manageable. }\end{array}$ & $\begin{array}{l}\text { Reduce debt to create space for } \\
\text { medium-term priorities. Although } \\
\text { Mexico has some fiscal space, it } \\
\text { should not be used to stimulate the } \\
\text { economy. Continued reduction in } \\
\text { public debt in relation to GDP would } \\
\text { create room to address the medium- } \\
\text { term needs for social and } \\
\text { infrastructure spending. }\end{array}$ \\
\hline Morocco & $\begin{array}{l}\text { Morocco has some fiscal space, reflecting moderate gross } \\
\text { financing needs, a balanced composition of debt, and manageable } \\
\text { medium and long-term adjustment needs. The debt sustainability } \\
\text { analysis also shows that public debt, which rose from } 47 \text { percent of } \\
\text { GDP in } 2009 \text { to } 64.7 \text { percent of GDP in } 2016 \text {, remains sustainable, } \\
\text { resilient to various shocks, and below the benchmark of } 70 \text { percent } \\
\text { of GDP for emerging markets. }\end{array}$ & $\begin{array}{l}\text { Fiscal reforms should continue to } \\
\text { increase policy space and support } \\
\text { growth and social spending for the } \\
\text { most vulnerable. Building on ongoing } \\
\text { progress in fiscal consolidation, this } \\
\text { will require: efforts to enhance public } \\
\text { revenues; civil service reform; careful } \\
\text { implementation of fiscal } \\
\text { decentralization; and, strengthened } \\
\text { state-owned enterprise oversight. }\end{array}$ \\
\hline Nigeria & $\begin{array}{l}\text { Non-oil revenue mobilization, coupled with a continued focus on } \\
\text { improving expenditure efficiency and composition, is essential to } \\
\text { create the fiscal space necessary to ensure debt sustainability and } \\
\text { scale-up capital expenditure. }\end{array}$ & $\begin{array}{l}\text { Larger and more frontloaded } \\
\text { adjustment than planned. With debt } \\
\text { service relative to revenue at } \\
\text { abnormally high levels, staff } \\
\text { recommends a larger and much more } \\
\text { frontloaded fiscal adjustment than } \\
\text { currently planned, to create the fiscal } \\
\text { space for this higher spending while } \\
\text { reducing the non-oil primary deficit. }\end{array}$ \\
\hline Pakistan & $\begin{array}{l}\text { Pakistan's fiscal space is limited based on economic } \\
\text { considerations and national fiscal rules. High debt levels and gross } \\
\text { financing needs point to remaining vulnerabilities, and cautiously } \\
\text { favorable medium-term debt dynamics in the baseline scenario are } \\
\text { subject to adverse shocks to growth, the primary balance, and debt } \\
\text { rollovers. An increase in external financing costs could also put a } \\
\text { strain on international reserves. In addition, public debt and the } \\
\text { fiscal deficit are projected to be above the ceilings set in the Fiscal } \\
\text { Responsibility and Debt Limitation Act. }\end{array}$ & $\begin{array}{l}\text { Fiscal policy should focus on } \\
\text { consolidation. With limited fiscal } \\
\text { space and a favorable growth outlook, } \\
\text { fiscal policy efforts should focus on } \\
\text { consolidation. Gradual fiscal } \\
\text { consolidation should continue } \\
\text { through the medium term, addressing } \\
\text { debt-related vulnerabilities and } \\
\text { reducing pressures on the current } \\
\text { account deficit and reserves. }\end{array}$ \\
\hline Philippines & $\begin{array}{l}\text { The Philippines has some fiscal space. Prudent fiscal } \\
\text { management, paired with strong economic growth, has lowered } \\
\text { general government net debt from } 68 \text { percent of GDP in } 2003 \text { to } \\
34.6 \text { percent in 2016. Both gross financing and long-term } \\
\text { adjustment needs are manageable, although external financing } \\
\text { requirements and debt held by nonresidents remain somewhat } \\
\text { elevated. There is low risk of debt stress both under the baseline } \\
\text { and an expansionary scenario, but some vulnerability to macro-fiscal } \\
\text { shocks such as lower GDP growth, contingent liabilities, and natural } \\
\text { disasters. }\end{array}$ & $\begin{array}{l}\text { Fiscal space should be used to } \\
\text { increase productive public } \\
\text { investment in physical and human } \\
\text { capital over the medium term. } \\
\text { However, with the output gap now } \\
\text { closed, fiscal policy should be } \\
\text { calibrated to balance against the risk } \\
\text { of overheating. Accordingly, a tighter } \\
\text { fiscal stance would be appropriate if } \\
\text { economic growth turns out to be } \\
\text { stronger than expected in } 2018 \text { and } \\
\text { beyond. }\end{array}$ \\
\hline
\end{tabular}




\begin{tabular}{|c|c|c|}
\hline Country & Bottom-line Assessment & Policy Advice \\
\hline Poland & $\begin{array}{l}\text { Although Poland may have some fiscal space for discretionary } \\
\text { stimulus given its current debt position, the fiscal space is limited if } \\
\text { one takes into account the fiscal rules. The need to create space to } \\
\text { respond to future shocks coupled with the need to accommodate } \\
\text { future aging costs and public investment spending imply that fiscal } \\
\text { consolidation should start as soon as possible, at the time when the } \\
\text { economy is strong. }\end{array}$ & $\begin{array}{l}\text { Consolidation should start as soon } \\
\text { as possible. Need to create space to } \\
\text { respond to future shocks coupled with } \\
\text { the need to accommodate future } \\
\text { aging costs and public investment } \\
\text { spending, at the time when the } \\
\text { economy is strong. The fiscal policy } \\
\text { priorities are to avoid breaching the } \\
\text { Excessive Deficit Procedure (EDP) limit } \\
\text { and to start consolidation as soon as } \\
\text { possible to reach the medium-term } \\
\text { objective of a structural deficit of } 1 \\
\text { percent of GDP. }\end{array}$ \\
\hline Russia & $\begin{array}{l}\text { Some fiscal space exists from the low debt level and the limited } \\
\text { financing needs. Because the recovery is gaining momentum, the } \\
\text { balanced fiscal adjustment path over the next three years is } \\
\text { appropriate; it will allow a steady adjustment to permanently lower } \\
\text { oil prices and to rebuild buffers in the face of potentially volatile oil } \\
\text { prices. }\end{array}$ & $\begin{array}{l}\text { Steady adjustment to lower oil } \\
\text { prices and build buffers. A steady } \\
\text { adjustment to permanently lower oil } \\
\text { prices and to rebuild buffers in the } \\
\text { face of potentially volatile oil prices, } \\
\text { even if some fiscal space exists from } \\
\text { the low debt level and the limited } \\
\text { financing needs. }\end{array}$ \\
\hline $\begin{array}{c}\text { Saudi } \\
\text { Arabia }\end{array}$ & $\begin{array}{l}\text { Saudi Arabia has some fiscal space. The strong fiscal buffers, the } \\
\text { availability of financing, and the current cyclical position of the } \\
\text { economy mean that rapid fiscal consolidation is neither necessary } \\
\text { nor desirable. }\end{array}$ & $\begin{array}{l}\text { More gradual consolidation. Saudi } \\
\text { Arabia has some fiscal space that can } \\
\text { be used for a more gradual fiscal } \\
\text { consolidation that balances the } \\
\text { budget by } 2022 \text { rather than in } 2019 \text { as } \\
\text { originally set out in the Fiscal Balance } \\
\text { Program. A well-paced fiscal } \\
\text { adjustment will limit the negative } \\
\text { short-term impact on growth and } \\
\text { enable the beneficial effects of } \\
\text { structural reforms to support growth } \\
\text { as fiscal consolidation continues over } \\
\text { the medium-term. }\end{array}$ \\
\hline South Africa & $\begin{array}{l}\text { Fiscal space is limited, consistent with the rising debt, sizable } \\
\text { contingent liabilities, the relatively high cost of government } \\
\text { borrowing, and significant uncertainties regarding the future path of } \\
\text { economic growth and interest rates. Abiding by the approved } \\
\text { budget ceilings is necessary to preserve investor confidence. }\end{array}$ & $\begin{array}{l}\text { Consolidation while safeguarding } \\
\text { recovery. Implementation of this } \\
\text { year's approved budget and of the } \\
\text { envisaged moderate improvement in } \\
\text { the structural fiscal balance in the next } \\
\text { few years will be key to strengthening } \\
\text { confidence and maintaining debt } \\
\text { sustainability, while safeguarding a } \\
\text { fragile recovery. }\end{array}$ \\
\hline Thailand & $\begin{array}{l}\text { Thailand has some fiscal space. The current cost of debt financing } \\
\text { is low but likely to increase in the medium term. Public debt and } \\
\text { gross financing needs paths are below standard vulnerability } \\
\text { benchmarks and below the Cabinet debt ceiling of } 60 \text { percent of } \\
\text { GDP. Age-related spending is projected to increase steadily for } \\
\text { demographic reasons, threatening fiscal sustainability beyond the } \\
\text { medium term. Risks of contingent liabilities are hard to quantify } \\
\text { with the available information. }\end{array}$ & $\begin{array}{l}\text { The existing fiscal space should be } \\
\text { used for large infrastructure projects } \\
\text { that remain macro-critical. It would } \\
\text { require stronger implementation } \\
\text { capacity and a modest revenue effort } \\
\text { to stabilize debt in the medium term. } \\
\text { More ambitious revenue mobilization } \\
\text { is needed over the long term given } \\
\text { rising age-related spending }\end{array}$ \\
\hline
\end{tabular}




\begin{tabular}{|c|l|l|}
\hline Country & \multicolumn{1}{|c|}{ Bottom-line Assessment } & \multicolumn{1}{c|}{ Policy Advice } \\
\hline \multirow{5}{*}{ Turkey } & $\begin{array}{l}\text { Turkey has some fiscal space. Access to financing remains solid, } \\
\text { despite some increase in costs. The fiscal position is sound: the } \\
\text { debt-to-GDP ratio is moderate and is projected to eventually } \\
\text { resume its declining trend under the baseline and most stress } \\
\text { scenarios; gross financing needs are low, and projected primary } \\
\text { balances exceed the debt-stabilizing level over the medium term. } \\
\text { However, persistent external imbalances, and dependency of the } \\
\text { banking and corporate sectors on external markets with substantial } \\
\text { rollover needs, call for prudence in using the fiscal space. }\end{array}$ & $\begin{array}{l}\text { Provide temporary stimulus. Turkey } \\
\text { has some fiscal space to provide the } \\
\text { recommended temporary stimulus. } \\
\text { Avoiding an excessive slowdown is } \\
\text { essential in the short run, and a large } \\
\text { fall in GDP growth could lead to a } \\
\text { vicious credit-income contraction } \\
\text { cycle. }\end{array}$ \\
\hline
\end{tabular}




\section{Annex III. Indicators of Contingent Liabilities}

\begin{tabular}{|c|c|c|c|}
\hline Indicator & Definition & Rationale & Data Source \\
\hline $\begin{array}{l}\text { Fiscal Costs of Financial Sector } \\
\text { Support }\end{array}$ & $\begin{array}{l}\text { Direct fiscal outlays due to } \\
\text { financial sector rescue packages in } \\
\text { the past (percent of GDP) }\end{array}$ & $\begin{array}{l}\text { NPLs may be low prior to a crisis } \\
\text { and may not give a sense of fiscal } \\
\text { costs of the bank recapitalization }\end{array}$ & $\begin{array}{l}\text { Laeven and Valencia (2012); Eurostat; } \\
\text { Bova and others (2016) }\end{array}$ \\
\hline Size of the Financial Sector & $\begin{array}{l}\text { Assets of domestic financial sector } \\
\text { (percent of GDP) }\end{array}$ & $\begin{array}{l}\text { Oversized financial sector can } \\
\text { impose large fiscal costs in case of } \\
\text { bank failures }\end{array}$ & $\begin{array}{l}\text { International Financial Statistics; } \\
\text { National Central Banks; Bova and } \\
\text { others (2016) }\end{array}$ \\
\hline Cost of Natural Disasters & $\begin{array}{l}\text { Average cost of damage of past } \\
\text { episodes (percent of GDP) }\end{array}$ & $\begin{array}{l}\text { Infrequent but can result in large } \\
\text { fiscal costs }\end{array}$ & $\begin{array}{l}\text { EM-DAT: The International Disaster } \\
\text { Database, CRED; Bova and others } \\
\text { (2016) }\end{array}$ \\
\hline $\begin{array}{l}\text { Liabilities of State-Owned } \\
\text { Enterprises }\end{array}$ & Total debt (percent of GDP) & $\begin{array}{l}\text { SOEs can be a source of quasi- } \\
\text { fiscal operations }\end{array}$ & $\begin{array}{l}\text { Government Finance Statistics; } \\
\text { National Ministries of Finance; Bova } \\
\text { and others (2016) }\end{array}$ \\
\hline Corporate Debt & $\begin{array}{l}\text { Non-financial sector corporate } \\
\text { debt-to GDP ratio }\end{array}$ & $\begin{array}{l}\text { Private debt overhang may lead to } \\
\text { bank failures and fiscal support }\end{array}$ & Global Debt Database \\
\hline PPPs & $\begin{array}{l}\text { Size of outstanding PPPs projects } \\
\text { (percent of GDP) }\end{array}$ & $\begin{array}{l}\text { The use of PPPs has begun to } \\
\text { increase significantly in recent } \\
\text { years and governments typically } \\
\text { do not cap exposures. Fiscal cost } \\
\text { typically spans over a long period } \\
\text { (i.e. the duration of the PPP } \\
\text { agreement). }\end{array}$ & $\begin{array}{l}\text { World Bank (Private Participation in } \\
\text { Infrastructure Advisory Facility - PPIAF); } \\
\text { Bova and others (2016) }\end{array}$ \\
\hline Legal claims & $\begin{array}{l}\text { Potential legal costs from court } \\
\text { decisions mandating } \\
\text { compensation payments }\end{array}$ & $\begin{array}{l}\text { Legal cases are a large although a } \\
\text { relatively infrequent source of risk }\end{array}$ & $\begin{array}{l}\text { Fiscal risk reports; Bova and others } \\
\text { (2016) }\end{array}$ \\
\hline Stock-Flow Adjustments & $\begin{array}{l}\text { 10-year average stock-flow } \\
\text { adjustments }\end{array}$ & $\begin{array}{l}\text { Easily calculated even with limited } \\
\text { fiscal data }\end{array}$ & DSA \\
\hline
\end{tabular}

\section{CInternational Monetary Fund. Not for Redistribution}




\section{References}

Ahuja, A., K. Wiseman, M. Syed, 2017, "Assessing Country Risk: Selected Approaches" IMF Technical Notes and Manuals No. 17/08. Appendix C, Section IV. http://www.imf.org/en/publications/tnm/issues/2017/06/01/assessing-country-risk-selectedapproaches-44959

Baum, A., A. Hodge, A. Mineshima, M. Moreno Badia, and R. Tapsoba, 2017, "Can they Do it All? Fiscal Space in Low-Income Countries", IMF Working Paper WP/17/110.

Blanchard, O., G. Dell'Ariccia, and P. Mauro. 2010, "Rethinking Macroeconomic Policy." Journal of Money, Credit and Banking 42 (Supplement 1): 199-215.

Bova, E., Ruiz-Arranz, M., Toscani, F., and E. Ture, 2016, "The Fiscal Costs of Contingent Liabilities: A New Dataset", IMF Working Paper 16/14.

Buffie and others, 2012, "Public Investment, Growth, and Debt Sustainability: Putting Together the Pieces", IMF Working Paper 12/144. https://www.imf.org/external/pubs/ft/wp/2012/wp12144.pdf

Celasun, O., G. Grigoli, K. Honjo, J. Kapsoli, A. Klemm, B. Lissovolik, J. Luksic, M. Moreno Badia, J. Pereira, M. Poplawski-Ribeiro, B. Shang, and Y. Ustyugova, 2015, "Fiscal Policy in Latin America : Lessons and Legacies of the Global Financial Crisis", Staff Discussion Note 15/6, International Monetary Fund, Washington (D.C.).

Clements, B., K. Dybczak, V. Gaspar, S. Gupta, and M. Soto, 2015, "The Fiscal Consequences of Shrinking Populations", Staff Discussion Note 15/21 (Washington: International Monetary Fund).

Cottarelli, C., and R. Moghadam, 2011, "Modernizing the Framework for Fiscal Policy and Public Debt Sustainability Analysis." https://www.imf.org/external/np/pp/eng/2011/080511.pdf

Daniel, J., J. Davis, M. Fouad, and C. Van Rijckeghem, 2006, "Fiscal Adjustment for Stability and Growth", IMF Pamphlet 55, International Monetary Fund, Washington (D.C.).

Diaz-Kalan, F., A. Popescu, and J. Reynaud, 2018, "Though Shalt Not Breach: Cost of Not Complying with Fiscal Rules in the European Union", IMF Working Paper (forthcoming), International Monetary Fund, Washington (D.C.).

Eurostat, 2018, "What is the Extent of Contingent Liabilities and Nonperforming Loans in the EU Member States?" Eurostat News release. http://ec.europa.eu/eurostat/web/products-pressreleases/-/2-29012018-AP 
Eyraud, L., X. Debrun, A. Hodge, V. Lledó, and C. Pattillo, 2018, "Second-Generation Fiscal Rules: Balancing Flexibility, Simplicity and Enforceability," Staff Discussion Note 18/X, International Monetary Fund, Washington (D.C.).

Furman, J., 2016, "The New View of Fiscal Policy and Its Application", Conference: Global Implications of Europe's Redesign, New York.

Gaspar, V., M. Obstfeld, and R. Sahay, 2016, "Macroeconomic Management when Policy Space is Constrained: A Comprehensive, Consistent, and Coordinated Approach to Economic Policy." IMF Staff Discussion Notes No. 16/09, International Monetary Fund, Washington (D.C.).

Gupta, S., A. Kangur, C. Papageorgiou, and W. Abdoul, 2014, "Efficiency-Adjusted Public Capital and Growth." World Development, Vol. 57, pp. 164-178.

International Monetary Fund, 2012a, "Balancing Fiscal Policy Risks", April 2012 Fiscal Monitor, International Monetary Fund, Washington (D.C.).

_ 2012b, "Fiscal Accountability, Transparency and Risk" (Washington: International Monetary Fund).

_ 2012c, "Macroeconomic Policy Frameworks for Resource-Rich Developing Countries", Washington. http://www.imf.org/external/np/pp/eng/2012/082412.pdf.

2013, "Reassessing the Role and Modalities of Fiscal Policy in Advanced Economies", IMF Policy Paper, International Monetary Fund, Washington (D.C.).

2014, "Government Finance Statistics Manual 2014" http://www.imf.org/external/Pubs/FT/GFS/Manual/2014/gfsfinal.pdf

2015, "The Commodities Roller Coaster; A Fiscal Framework for Uncertain Times", Fiscal Monitor, Oct 2015, International Monetary Fund, Washington (D.C.).

_ 2016a, "Analyzing and Managing Fiscal Risks: Best Practices," (Washington: International Monetary Fund).

_ 2016b, "Assessing Fiscal Policy: An Initial Consistent Set of Considerations", International Monetary Fund, Washington (D.C.).

_ 2016c, "Debt: Use it Wisely," Chapter 1 of the October 2016 Fiscal Monitor "Debt: Use it Wisely", International Monetary Fund, Washington (D.C.).

2016d, "Fiscal Policy: How to adjust to a Large Fall in Commodity Prices", Fiscal Affairs Department How To Notes, International Monetary Fund, Washington (D.C.). 
2016e, "How to Assess Fiscal Implications of Demographic Shifts: A Granular Approach." Fiscal Affairs Department How To Note, International Monetary Fund, Washington (D.C.).

2017a, "A Greater Role for Fiscal Policy", Chapter 1 of the April 2017 Fiscal Monitor "Doing More With Less." International Monetary Fund, Washington (D.C.).

2017b, "Eligibility to Use the Fund's Facilities for Concessional Financing for 2017", IMF Policy Paper, International Monetary Fund, Washington (D.C.). https://www.imf.org/en/Publications/Policy-Papers/Issues/2017/05/23/pp052317-eligibilityto-use-the-fund-facilities-for-concessional-financing-for-2017

2018a, "How to Select Fiscal Rules: A Primer" How-to Note, International Monetary Fund, Washington (D.C.).

2018b, "How to Calibrate Fiscal Rules: A Primer", How-to Note, International Monetary Fund, Washington (D.C.).

Laeven, L. and F. Valencia, 2012, "Systemic Banking Crises Database: An Update", IMF Working Paper 12/163. https://www.imf.org/ /media/Websites/IMF/importeddatasets/external/pubs/ft/wp/2012/Data/wp12163.ashx

Melina, G., S. Yang and L. Zanna, 2014, "Debt Sustainability, Public Investment, and Natural Resources in Developing Countries : the DIGNAR Model", IMF Working Paper 14/50. https://www.imf.org/en/Publications/WP/Issues/2016/12/31/Debt-Sustainability-PublicInvestment-and-Natural-Resources-in-Developing-Countries-the-41455

OECD, 2016, "A Re-Assessment of Fiscal Space in OECD Countries," OECD Working Paper, ECO/WKP (2016)76, Paris, France.

Pennings, S., 2017, "Long Term Growth Model (LTGM v4.0) - Model Description" http://pubdocs.worldbank.org/en/887381517952394875/Model-Outline-V4Public.pdf

Schaechter and others, 2011, "A Toolkit to Assessing Fiscal Vulnerabilities and Risks in Advanced Economies", IMF Working Paper 12/11.

United Nations (UN), 2017, "World Population Prospects: The 2017 Revision." New York: United Nations. http://esa.un.org/wpp/

Weber, A., 2012, "Stock-Flow Adjustments and Fiscal Transparency: A Cross-Country Comparison", IMF Working Paper 12/39. https://www.imf.org/en/Publications/WP/Issues/2016/12/31/Stock-Flow-Adjustments-andFiscal-Transparency-A-Cross-Country-Comparison-25692 
World Bank, 2015, "The Economics of the Macro-Fiscal Model", (Washington: World Bank) 